\title{
Risks and Complications of Coronary Angiography: A Comprehensive Review
}

\author{
Morteza Tavakol MD, Salman Ashraf MD \& Sorin J. Brener MD \\ New York Methodist Hospital \\ United States of America
}

Received: October 10, 2011 Accepted: November 17, 2011 Published: January 1, 2012

doi:10.5539/gjhs.v4n1p65 URL: http://dx.doi.org/10.5539/gjhs.v4n1p65

\begin{abstract}
Coronary angiography and heart catheterization are invaluable tests for the detection and quantification of coronary artery disease, identification of valvular and other structural abnormalities, and measurement of hemodynamic parameters. The risks and complications associated with these procedures relate to the patient's concomitant conditions and to the skill and judgment of the operator. In this review, we examine in detail the major complications associated with invasive cardiac procedures and provide the reader with a comprehensive bibliography for advanced reading.
\end{abstract}

Keywords: Cardiac catheterization, Angiography, Contrast material, Acute kidney injury, Complications

\section{Introduction}

Coronary angiography is the gold standard test for identifying the presence and extent of atherosclerotic coronary artery disease (CAD). As with any invasive procedure, there are specific patient-dependent and procedure-related complications that are inherent to the test. Complications range widely from minor problems with short term sequelae to life threatening situations that may cause irreversible damage, if urgent care is not provided. Fortunately, the associated risks have decreased significantly since the inception of coronary arteriography due to advanced equipment design, improved peri-procedural management, and increased experience of diagnostic centers and operators.

Although there are no absolute contraindications to performing coronary arteriography, the associated risks can be attributed to cardiac and non-cardiac complications. Specific disease states pertaining to the general medical profile of the patient (older age, renal insufficiency, uncontrolled diabetes mellitus, and morbid obesity) can increase the risk for complications. The underlying cardiovascular status of the patient can further predispose to adverse events. The extent of CAD, congestive heart failure (CHF) with low ejection fraction, recent stroke or myocardial infarction (MI), and bleeding propensity are just a few of the cardiovascular characteristics that can increase cardiac and vascular complications. Furthermore, the type of procedure being performed, be it diagnostic coronary angiography or additional percutaneous coronary intervention, modulates the risk.

Given the above considerations, however, major complications are uncommon. Because major complications from cardiac catheterization occur in less than $2 \%$ of the population, with mortality of less than $0.08 \%$, there are relatively few patients who cannot be studied safely in an experienced laboratory. The use of iso-osmolar contrast media, lower profile diagnostic catheters, measures to reduce the incidence of bleeding and extensive operator experience can all serve to reduce the already low incidence of such complications even further. Therefore, the procedure can be successfully performed even in the most critically ill patient, when clinically indicated, with relatively low risk. However, the risk-to-benefit ratio of cardiac catheterization and familiarity with potential benefits and risks must be assessed on an individual basis in order to minimize any potential problems. In this chapter, we aim to identify the risks associated with coronary angiography and coronary interventions in the modern catheterization laboratory, and describe advances in equipment design and management protocols that have been promoted to reduce potential complications. 


\section{Allergic and Adverse Reactions}

\subsection{Local Anesthesia}

Allergic local and systemic reactions to local anesthesia are extremely rare. Methemglobinemia, asthma-like reactions, vasodepressor reaction and anesthesia toxicity have been reported (Finder \& Moore, 2002). Most reports are with the older agents and have been infrequently reported with amide agents, such as lidocaine. Reactions are generally dermatologic or vagal, and are rarely anaphylactic. The reactions that do occur are generally secondary to the preservatives used in drug preparations. Use of preservative-free agents, such as bupivacaine, and skin testing would be warranted in patients with history of reactions to local anesthetics (T. Feldman, Moss, Teplinsky, \& Carroll, 1990).

\subsection{General Anesthesia}

General anesthesia is not routinely required in the catheterization laboratory, and the vast majority of procedures occur without the presence of an anesthesiologist. Conscious sedation and analgesia with short acting agents such as midazolam or fentanyl at low doses are, however, commonly used to increase patient comfort and relieve anxiety during the procedure. In such cases, care must be taken to avoid over-sedation of the patient. Close monitoring of blood pressure, heart rate, respiratory rate and oxygenation should be performed in all patients. When hemodynamic compromise or oversedation occurs, the use of reversal agents for benzodiazepines (flumazenil) and opiates (naloxone) should be promptly administered. Anaphylactoid reactions happen infrequently with conscious sedation agents and are much more likely to occur following administration of contrast media. Treatment of any adverse reaction depends on its severity, and includes the potential use of oxygen, bronchodilators, epinephrine, histamine blockers, corticosteroids and intravenous fluids (Dewachter, Mouton-Faivre, \& Emala, 2009). In cases of severe anaphylaxis not responsive to conservative management, endotracheal intubation and urgent consultation with anesthesia team must be performed. Proper history and review of allergies can help avoid unnecessary exposure to patients with previous allergy or adverse reactions to local or systemic anesthesia. Particular attention should be paid to allergy to sea food, as there is possible cross-reactivity with iodine-containing contrast media.

\subsection{Contrast Media}

Adverse reactions from contrast media may be classified as chemotoxic or anaphylactoid. Contrast media stimulate an anaphylactoid response through histamine release. It differs from an anaphylactic reaction, in that it is not immune-mediated and does not require prior sensitization to the offending agent to initiate a reaction. Chemotoxic effects are primarily related to the hyperosmolarity, ionic content, viscosity, and calcium binding properties of these agents (Goss, Chambers, \& Heupler, 1995). All contrast agents are based exclusively on iodine, commonly combined to a benzoic acid ring in a mixture of meglumine or sodium salt of diatrizoid acid with calcium EDTA. The concentrations of sodium and EDTA are kept roughly equal to that of blood, as higher or lower concentrations have been associated with tachyarrhythmia and myocardial depression. In order to achieve the iodine concentration that is needed for optimal visualization during angiography, solutions of conventional contrast agents were extremely hypertonic. The resulting solutions of these agents (Hypaque (Nycomed) and Angiovist (Berlex)) have an osmolality about 5.8 times $(1690 \mathrm{mOsm} / \mathrm{kg})$ that of plasma (Barrett et al., 1992). Adverse reactions are common in the ionic, high osmolality contrast agents, reported in $>50 \%$ of patients in some studies (Matthai et al., 1994). Milder constitutional symptoms are frequently reported (warmth, pain, chest tightness, nausea and vomiting) and are self-limited in the majority of cases. Adverse reactions requiring intervention (hypotension, bradyarrhythmias, pulmonary congestion) have been reported in nearly $30 \%$ of patients in one randomized trial (Barrett et al., 1992).

The introduction of lower osmolar, ionic agents (ioxaglate (Hexabrix)), and water soluble low-osmolar, non-ionic (iohexol (Omnipaque), ioxilan (Oxilan)) have significantly reduced the incidence of hypersensitivity and adverse reactions. In randomized clinical trials, the use of high osmolar contrast material was associated with a $3.1 \%$ increase in risk for need to treat patients for adverse reactions and 3.6\% increase in life threatening reactions in comparison to use of lower osmolar non-ionic agents. These reactions were largely confined to patients with severe coronary artery disease or unstable angina (Barrett et al., 1992). These results have been duplicated in two other randomized trials that were able to further risk stratify patients at highest risk for developing adverse contrast reactions (Matthai et al., 1994; Steinberg et al., 1992). Patients with advanced age, higher New York Heart Association CHF class, history of prior contrast reaction, and elevated left ventricular diastolic pressure have been identified as being up to six times more likely to develop adverse reactions with high osmolar ionic agents (Matthai et al., 1994). The need for risk stratification initially arose from the high cost of the newer low osmolar agents, which was at one point 10-20 times that of conventional high osmolar agents 
(Barrett et al., 1992). Selective use of these agents in appropriate populations has been shown to decrease overall cost by $66 \%$ with improvement in safety and cost-effectiveness (Matthai et al., 1994). The cost of these agents, however, has decreased significantly over the past 10 years allowing for more widespread use of the low osmolar agents to prevent adverse reactions at only a small incremental difference in price.

Most recently, a non-ionic, iso-osmolar compound (iodixanol (Visipaque) has been developed that has an osmolality similar to that of blood $(290 \mathrm{mOsm} / \mathrm{kg})$. Hypersensitivity reactions occurred in only $0.7 \%$ of the population studied in a large randomized trial comparing iodixanol to the ionic, low osmolar agent ioxaglate, without a significant difference in major cardiovascular events (Bertrand, Esplugas, Piessens, \& Rasch, 2000). The introduction of the non-ionic agents was initially met with some concern due to evidence that ionic contrast material exhibited a more pronounced antiplatelet and antithrombotic activity, especially in in-vitro studies. These properties may be beneficial during a procedure that may damage the vascular endothelium and cause thrombosis. Fortunately, no increase in the risk of thrombotic complications or major cardiovascular events has been demonstrated in large randomized multicenter trials of angioplasty in which the two classes of contrast agents were compared (Bertrand et al., 2000; Schrader et al., 1999)

\subsection{Prophylaxis and Treatment}

Prevention of allergic reactions to contrast material can be successfully achieved. There are two categories of patients at risk for developing anaphylaxis that should be considered for pre-treatment. Patients with previous anaphylactic reactions are at highest risk for developing recurrent reactions. The second category consists of patients with history of atopy, asthma or those who take beta adrenergic blockers, in whom a twofold risk in anaphylaxis has been reported (Lang, Alpern, Visintainer, \& Smith, 1991). Despite general concerns, no consistent cross-reactivity has been demonstrated in patients with allergies to food containing iodine (seafood) and contrast anaphylaxis risk (Goss et al., 1995; Hildreth, 1987). When encountering patients with history of allergy to shellfish or seafood, further questioning should be addressed toward history of atopy or asthma, as this would identify the patients at highest risk for developing anaphylaxis. In addition to the type of contrast agent, pre-treatment with prophylactic medications is a critical part of preventing recurrent reactions in the population at highest risk. Corticosteroids and histamine blockers are the cornerstone of pretreatment. Prednisone $50 \mathrm{mg}$ administered 13, 7, and 1 hour before the procedure together with diphenhydramine $50 \mathrm{mg}$ orally 1 hour before the procedure are effective in reducing recurrent reactions (Bush \& Swanson, 1991; Goss et al., 1995; Greenberger, Halwig, Patterson, \& Wallemark, 1986; Nayak, White, Cavendish, Barker, \& Kandzari, 2009; Wittbrodt \& Spinler, 1994). For urgent procedures, intravenous hydrocortisone $200 \mathrm{mg}$ with $50 \mathrm{mg}$ of diphenhydramine should be used prior to the procedure (Table 1) (Greenberger et al., 1986).

\section{$<$ Table 1>}

It has been hypothesized that the addition of Histamine-2 blockers (cimetidine or ranitidine) to the above regimen may provide greater antihistamine effect on the vascular system in addition to diphenhydramine, a conventional Histamine-1 blocker. The low cost and high safety profile of Histamine-2 blockers have made them a common component of treatment in many catheterization laboratories. Its effectiveness, however, is controversial, and consistent results have not been shown in prospective trials (Goss et al., 1995; Greenberger et al., 1986; Myers \& Bloom, 1981; Wittbrodt \& Spinler, 1994). Monteleukast has also been advocated as therapeutic addition. The use of Histamine-2 blockers and Monteleukast has not been advocated by the American College of Radiology (American College of Radiology, 2010).

Despite adequate pre-medication, breakthrough reactions have been shown to occur (Freed, Leder, Alexander, DeLong, \& Kliewer, 2001), stressing the role of awareness and careful monitoring in this group of patients. In the case of anaphylactic reactions with laryngeal edema and vascular compromise, $0.3 \mathrm{ml}$ epinephrine at a dilution of 1:1000 subcutaneously or $3 \mathrm{ml}$ at dilution of 1:10,000 intravenously or subcutaneously should be administered immediately. Corticosteroids, diphenhydramine and large volume intravenous fluids should also be given to decrease the severity of the reaction. The use of Histamine-2 blockers remains controversial but should be considered in treatment of refractory cases (Bush \& Swanson, 1991; Goss et al., 1995).

\subsection{Heparin Induced Thrombocytopenia}

Heparin Induced Thrombocytopenia (HIT) is a serious immune-mediated complication of heparin administration from flush heparinized saline or during percutaneous coronary interventions. Although the risk will not be manifest during the procedure, the clinical symptoms that develop in the days after the procedure can have potentially devastating thromboembolic complications in patients with prior exposure to heparin. Roughly 1-3\% of patients who receive unfractionated heparin will develop a serious form of immune mediated thrombocytopenia with associated venous and arterial thrombosis (HIT-2) (Brieger, Mak, Kottke-Marchant, \& 
Topol, 1998; Jang \& Hursting, 2005). This reaction is caused by antibodies binding to the heparin platelet factor-4 complex, which lead to a cascade of reactions causing platelet activation and the release of procoaggulant and inflammatory factors that consume platelets and incite thrombosis. Patients that develop HIT-2 usually experience a platelet count drop of at least 50\%, typically 5-15 days after initiation of heparin, or more suddenly following previous heparin sensitization (Jang \& Hursting, 2005). Patients with underlying coronary artery disease and patients with cardiac transplantation have a higher incidence of HIT (2-8\% and $11 \%$, respectively) (Hourigan, Walters, Keck, \& Dec, 2002; Kappers-Klunne et al., 1997), and several patients have been described in whom an acute coronary syndrome (manifesting as acute thrombosis) occurred during coronary angioplasty in association with the onset of HIT (Gupta, Savage, \& Brest, 1995). The diagnosis is based on the clinical picture of platelet decrease with or without associated thrombosis. HIT-antibody assays are routinely available for confirming the diagnosis, but treatment should not be delayed when there is a strong clinical suspicion due to severity of comorbidities. Among the patients with HIT and thrombosis, $9-11 \%$ require limb amputation and mortality is reported in $17-30 \%$ (Jang \& Hursting, 2005). Treatment includes immediate and complete discontinuation of heparin and initiation of treatment with direct thrombin inhibitors, such as argatroban, bivlaurdin, or lepirudin. In patients with, or at risk for HIT, who present to the catheterization laboratory, prospective trials of bivalirudin and argatroban have demonstrated safety and efficacy (Campbell et al., 2000; Lewis et al., 2002; Mahaffey et al., 2003). Bivalirudin dose needs adjustment in patients with severe renal impairment, while argatroban is contraindicated in patients with hepatic dysfunction.

\section{Infections}

\subsection{Incidence}

Infections are rare after invasive cardiovascular procedures. The reported incidence of catheter-related infections (not involving cut-down techniques) is much less than $<1 \%$ based on retrospective studies (Munoz et al., 2001; Ramsdale, Aziz, Newall, Palmer, \& Jackson, 2004). This may be an underestimation of the true incidence of infections acquired during catheterization, as most signs and symptoms are unlikely to develop immediately following the procedure. In a prospective study of 147 consecutive blood cultures obtained after complex cardiac catheterization procedures, positive blood cultures were found in $18 \%$ and $12 \%$ of the subjects immediately following and 12 hours after the procedure, respectively. The most common organism was coagulase negative staphylococcus and none of the patients developed clinical signs of infection (Ramsdale et al., 2004).

Fever is a relative contraindication for elective procedures. Patients with ongoing infections should be appropriately treated before an elective cardiac catheterization (Chambers et al., 2006). Certain catheterization techniques have been shown in case studies to increase the risk of infectious complications. Local infections after angioplasty have been related to early re-puncture of ipsilateral femoral artery (Wiener \& Ong, 1989), use of arterial grafts for access (McCready et al., 1991), and retention of catheters for prolonged periods (Polanczyk et al., 2001). Local hematomas can be a nidus of infection and should be treated urgently upon occurrence. Infection of the suture or collagen anchor in vascular closure devices are infrequent $(0.5 \%)$, but can lead to limb-threatening arteritis when they occur (Baddour et al., 2004; Cooper \& Miller, 1999). Insertion of a Foley catheter prior to the procedure should be noted as a potential cause of complicated urinary tract infection. Their use should be avoided when possible and, when inserted, removed when urine output monitoring is not further warranted.

\subsection{Infectious Precautions}

The American College of Cardiology does not recommend the use of strict operating room sterile techniques for most catheterization procedures (Bashore et al., 2001; Chambers et al., 2006).

Hair removal should be considered if there is interference with obtaining access site. When removal is necessary, electric clippers should be used and the use of razors should be avoided (Chambers et al., 2006; Ko, Lazenby, Zelano, Isom, \& Krieger, 1992; O'Grady et al., 2002). Skin cleansing with a 2\% chlorhexadine based preparation such as Chloraprep should be used prior to local anesthesia. A recent study of $\sim 500$ patients did not detect any difference in the rate of infections when caps and masks were worn (Laslett \& Sabin, 1989). However, studies looking at the effectiveness of sterile techniques in the catheterization laboratory will require a large patient population in order to be sufficiently powered, given the low incidence of infection. Furthermore, the use of masks and eye shields may provide more protection to the operator to avoid blood splattering during the procedure. Following the procedure, the use of occlusive dressings and topical antimicrobials should be avoided as they can increase the risk of bacterial and fungal infections (Chambers et al., 2006). Antibiotic prophylaxis is not routinely indicated during cardiac catheterization (O'Grady et al., 2002). 


\section{Nephropathy}

Contrast Induced Nephropathy (CIN) is a potentially serious complication of coronary angiography with significant short and long term sequelae. CIN, however, can be minimized with proper risk stratification, selection of contrast agent and staging of procedures, along with preventive management strategies. CIN has been defined as rise in serum creatinine of $\geq 0.5 \mathrm{mg} / \mathrm{dl}$ or $25 \%$ above the baseline value, based on data that associated such increases with clinically relevant outcomes, such as permanent renal impairment requiring hemodialysis, and death (Gami \& Garovic, 2004). Varying definitions of CIN applied in studies with differences in patient co-morbidity have led to difficulty in assessing the true incidence of CIN, with reported rates ranging between 3.3-16.5\% (Murphy, Barrett, \& Parfrey, 2000). A large observational study in 1,826 consecutive patients uncovered an incidence of $14.4 \%$ in a community based population (McCullough, Wolyn, Rocher, Levin, \& O'Neill, 1997). Smaller prospective studies in patients with fewer risk factors have shown a much smaller risk, roughly 3\% (Rudnick, Berns, Cohen, \& Goldfarb, 1997). Most patients, fortunately, experience a mild, transient increase in serum creatinine that is typically not associated with oliguria, peaks within two to four days, and generally resolves by 7 days.

The pathogenesis of CIN appears to be multifactorial. Multidirectional changes in renal hemodynamics due to the effects of contrast media on a number of vasoactive substances (adenosine, nitric oxide, endothelin) along with direct cytotoxicity through the action of free radicals have been implicated as potential causes (Barrett \& Carlisle, 1993; R. Solomon, 2005). Preexisting renal insufficiency, diabetes, age, along with osmolality and volume of contrast used are the most significant risk factors to developing CIN. In retrospective studies of patients undergoing angiography, the incidence of CIN in patients with baseline creatinine $<2.0 \mathrm{mg} / \mathrm{dl}$ was higher among diabetic than nondiabetic patients. Amongst those with a baseline creatinine $\geq 2.0$, all had a significantly higher risk of acute renal failure. Of the 7,856 patients studied, the risk of CIN was only $2.5 \%$ when creatinine was $<2 \mathrm{mg} / \mathrm{dl}$, but rose to $30.6 \%$ when creatinine was $>3.0 \mathrm{mg} / \mathrm{dl}$ (Rihal et al., 2002). In patients who develop acute renal failure, the two largest studies have reported a nearly identical risk of $7.1 \%$ for suffering permanent kidney damage requiring hemodialysis (McCullough, Bertrand, Brinker, \& Stacul, 2006; Rihal et al., 2002). In addition, multiple studies have shown a correlation between CIN and poor long-term survival (Bartholomew et al., 2004; Freeman et al., 2002; Rihal et al., 2002) with the risk of renal injury requiring dialysis, recurrent hospitalization, and death increasing proportionally to the severity of acute kidney injury (James et al.). In large registries, $22 \%$ of patients with acute renal failure die during the index hospitalization, compared with only $1.4 \%$ of patients without acute renal failure. Among hospital survivors with acute renal failure, 1 and 5 year estimated mortality rates were $12.1 \%$ and $44.6 \%$, respectively; much greater than the $3.7 \%$ and $14.5 \%$ mortality rates in patients without acute renal failure (Rihal et al., 2002).

\subsection{Prevention and Prophylaxis}

Multiple individual risk factors have been reported for the development of CIN. Using multivariable regression models, risk scores have been developed that can assess the risk of CIN (Figure 1) (James et al.; Mehran et al., 2004). Of the modifiable variables, minimizing the volume of contrast medium administered is a primary defense against CIN. Radiocontrast dose was the most powerful independent predictor of nephropathy requiring dialysis (Cigarroa, Lange, Williams, \& Hillis, 1989; Marenzi et al., 2009; McCullough et al., 1997; Rudnick et al., 1997). The overall volume appears to be more relevant in patients with baseline chronic kidney disease, who have a 5-10 fold increase in CIN when more than 125-140 $\mathrm{ml}$ of contrast is administered, irrespective of other preventive measures (McCullough et al., 1997; Taliercio et al., 1991). Therefore, most experts recommend limitation of contrast volume to $3 \mathrm{ml} / \mathrm{kg}$.

\section{$<$ Figure 1>}

As previously discussed, the osmolality and ionic content of the selected contrast media have been closely related to a number of adverse reactions, including CIN (Barrett \& Carlisle, 1993; Jo et al., 2006; Lautin et al., 1991; McCullough et al., 2006; Rudnick et al., 1995). Aspelin et al. showed that the iso-osmolar nonionic Iodixanol (Visipaque) reduced the relative risk of CIN by $23 \%$ when compared to low-osmolar nonionic agent iohexol (Omnipaque) (Aspelin et al., 2003). The concept of osmolality being the sole contributor to CIN has been recently disputed by a randomized, double-blinded trial. The results of the CARE study failed to show any difference in CIN defined by multiple definitions following administration of non-ionic, low-osmolar Iopamidol in comparison to Iodixanol in high risk patients with or without diabetes mellitus (R. J. Solomon et al., 2007). A meta-analysis, conducted by the same investigator, also has shown little difference between agents whose osmolality is $<800 \mathrm{mOsm} / \mathrm{kg}$. Such data suggest that factors such as viscosity and ionic content, in addition to the osmolality of the agent chosen, contribute to the overall risk of developing CIN (R. Solomon, 2005). 
Volume expansion is the cornerstone for prevention of CIN. The effectiveness of saline administration is well documented by a series of small observational and randomized trials. The first controlled study to explore this relationship was performed in 1994 and showed that administration of $0.45 \%$ saline alone over 24 hours was more effective than the combination of volume supplementation and diuresis with furosemide or mannitol (R. Solomon, Werner, Mann, D'Elia, \& Silva, 1994). Mueller et al. addressed the tonicity of fluids in 1,383 patients, comparing $0.45 \%$ saline with $0.9 \%$ saline. The rate of CIN was greater in patients receiving $0.45 \%$ saline ( $2.0 \mathrm{vs}$ $0.7 \%, \mathrm{p}=0.04$ ), without any difference in outcomes for dialysis or length of stay (Mueller et al., 2002). Subsequent to this study, a series of underpowered randomized trials have shown a moderate, but consistent benefit of isotonic saline administration at a rate of $1 \mathrm{ml} / \mathrm{kg}$ over a 24 hour period, beginning 12 hours prior to the procedure (Bader et al., 2004; Krasuski, Beard, Geoghagan, Thompson, \& Guidera, 2003; Weisbord \& Palevsky, 2008). The success of peri-procedural hydration can be extended to patients with chronic renal failure through continuous veno-venous hemofiltration. Hemofiltration allows for administration of large volumes of fluid without the associated risk of fluid overload. In randomized trials, hemofiltration vs. standard therapy in patients with moderate to severe renal insufficiency (baseline creatinine $3.0 \mathrm{mg} / \mathrm{dl}$ ) lowered the absolute need for hemodialysis by $18 \%$, with additional reductions in in-hospital events and one-year mortality ( $10 \%$ vs. $30 \%$ for controls) (Marenzi et al., 2003). Prophylactic hemodialysis, however, has not shown the same benefits (Vogt et al., 2001).

The antioxidant agent acetylcysteine, $600-1200 \mathrm{mg}$ orally before and $600 \mathrm{mg}$ twice daily after the procedure for 24-48 hours, has shown inconsistent benefit in prevention of CIN (Briguori et al., 2007; Coyle et al., 2006; Diaz-Sandoval, Kosowsky, \& Losordo, 2002; Fung et al., 2004; Marenzi et al., 2006; Tepel et al., 2000; Webb et al., 2004). Meta-analysis of the available data up to 2003 showed that the addition of acetylcysteine to intravenous hydration led to a $56 \%$ relative reduction in CIN in comparison to hydration alone (Birck et al., 2003). Due to the cost effectiveness, feasibility of use, and benign side effect profile, many experts and institutions have advocated its routine use. A recent randomized international study in 2,303 patients from 46 hospitals across Brazil (ACT trial), however, has failed to show any benefit. In both groups, $12.7 \%$ of patients experienced CIN with similar elevations in serum creatinine and need for dialysis. This is the largest study conducted on the topic and may have answered the question on the potential benefit of acetylcysteine. ("Acetylcysteine for prevention of renal outcomes in patients undergoing coronary and peripheral vascular angiography: main results from the randomized Acetylcysteine for Contrast-induced nephropathy Trial (ACT)," 2011) Alkalinizing the urine with sodium bicarbonate infusion has been studied as an attractive mechanism to prevent CIN through attenuation of free radical formation(Brar et al., 2008). The results, however, have varied and failed to show a consistent benefit among trials.(From et al., 2008; Maioli et al., 2008; Merten et al., 2004; Recio-Mayoral et al., 2007) Most of the benefit appears to have been derived from smaller studies that assessed outcomes soon after radiocontrast administration (Zoungas et al., 2009). In some series, significant volume overload and heart failure have been reported after large volumes of sodium bicarbonate. Administration of ascorbic acid as an antioxidant, or the selective dopamine-1 agonist fenoldapam for promotion of renal plasma flow, has also failed to produce a consistent benefit.(Spargias et al., 2004; Stone et al., 2003)

\section{Cholesterol Emboli}

Cholesterol emboli are released as cholesterol crystals from friable vascular plaques. Distal embolization of cholesterol crystals after angiography, major vessel surgery, or thrombolysis causes a systemic syndrome.(Bashore \& Gehrig, 2003; Kronzon \& Saric) The diagnosis is suggested clinically by the appearance of discoloration of the extremities in a mottled purple pattern of livedo reticularis, or when there is digital cyanosis or gangrene, or neurological or renal involvement. Renal involvement is characteristically slowly progressing over a two to four week period following angiography. The diagnosis is confirmed through biopsy of affected tissues showing deposition of cholesterol crystals. Accompanying eosinophilia and elevated C-reactive protein are common laboratory features. The incidence reported in prospective studies is generally less than 2\%.(Fukumoto, Tsutsui, Tsuchihashi, Masumoto, \& Takeshita, 2003; Saklayen, Gupta, Suryaprasad, \& Azmeh, 1997) Interestingly, autopsy studies have reported a much higher incidence, in range of 25-30\%, indicating that many of these events are asymptomatic.(Fukumoto et al., 2003; Ramirez, O'Neill, Lambert, \& Bloomer, 1978) This is further supported by the discovery of plaque debris from $>50 \%$ of all guiding catheters in a prospective study of 1,000 patients (Keeley \& Grines, 1998). No significant difference in the risk of atheroembolism between brachial and femoral approaches exists, suggesting that the ascending aorta is the predominant source. Major risk factors include advanced age, repeat procedures, diffuse atherosclerotic disease, and elevated pre-procedure C-reactive protein. Treatment is mostly supportive but one retrospective study reported decreased incidence of cholesterol emboli with pre-procedural use of simvastatin.(Woolfson \& Lachmann, 1998) Besides 
statins, management with steroids and prostaglandins has not resulted in significant benefit.(Elinav, Chajek-Shaul, \& Stern, 2002; Graziani, Santostasi, Angelini, \& Badalamenti, 2001)

\section{Local Vascular Injury}

Vascular access site complications are among the most common and dreaded complications of coronary angiography, and are the most significant contributor to morbidity and mortality of the procedure. In the earlier days of cardiac catheterization, the incidence of vascular complications was reported to be between $0.7 \%-11.7 \%$ (Babu, Piccorelli, Shah, Stein, \& Clauss, 1989; Omoigui et al., 1995; Oweida, Roubin, Smith, \& Salam, 1990; Samal \& White, 2002; Wyman et al., 1988). Over the past decade there have been significant advances in anticoagulant and antiplatelet therapies that have decreased the incidence of major cardiovascular events at a risk of increased bleeding. Major post-procedural bleeding and blood transfusions are associated with increased length of stay and decreased long-term survival. (Doyle et al., 2008) Fortunately, increasing experience and strategies aimed at decreasing the risk of access site complications has paralleled improvements in pharmacotherapy. Increasing awareness of the significance of peri-procedural bleeding to overall morbidity and mortality has resulted in the development and validation of scores aimed at identifying patients that are at the highest risk of bleeding. (Applegate et al., 2006; Kinnaird et al., 2003; Mandak et al., 1998; Nikolsky et al., 2007) Analysis from the IMPACT II trial has identified modifiable risk factors, such as early sheath removal, avoiding placement of venous sheaths, and careful monitoring of heparin doses as potential ways of decreasing bleeding risk and complications.(Mandak et al., 1998) Increasing experience with these complications has allowed for heightened awareness along with earlier detection and treatment techniques. Attempts at optimizing vascular access via fluoroscopic delineation of anatomical landmarks and identifying potential complications via peripheral angiography have come into routine practice (Turi, 2005). Advances in equipment design allow use of lower profile catheters via smaller sheaths, decreasing vascular trauma, and causing fewer complications.(Applegate et al., 2008; Metz et al., 1997; Talley, Mauldin, \& Becker, 1995) The development of vascular closure devices has improved patient comfort following the procedure and, as development progresses further, could reduce the incidence of bleeding complications. Accordingly, these advances have resulted in significant decrease in vascular complications from 1998 to 2007. (diagnostic catheterization from $1.7 \%$ to $0.2 \%$, percutaneous coronary intervention from $3.1 \%$ to $1.0 \%$, respectively) (c).(Applegate et al., 2008)

\section{$<$ Figure 2>}

Most of the local vascular complications can be avoided with optimal placement of the sheath in the common femoral artery (Figure 3). The common femoral artery courses over the femoral head in $92 \%$ of cases, and $99 \%$ of the time the bifurcation of the common femoral artery was below the middle of the femoral head (Garrett, Eckart, Bauch, Thompson, \& Stajduhar, 2005), (Jacobi, Schussler, \& Johnson, 2009; Sherev, Shaw, \& Brent, 2005)'(Kim et al., 1992)

\section{$<$ Figure 3>}

\subsection{Hematoma and Retroperitoneal Hemorrhage}

Poorly controlled hemostasis following femoral sheath removal can result in a self-limited collection of blood in the anterior compartment of the thigh forming a hematoma. Most hematomas are benign, tender masses without connection to the accessed vessel. Larger hematomas, however, have been associated with formation of deep vein thrombosis and nerve compression resulting in sensory loss.(Butler \& Webster, 2002; Shammas, Reeves, \& Mehta, 1993) Large hematomas requiring blood transfusion occurred in $2.8 \%$ of the population in a large single center registry from 2000-2005 (Table 2).(Doyle et al., 2008) Manual compression of the proximal femoral artery and hematoma immediately following discovery and examination should be initiated. From our experience, 20-30 minutes of manual compression results in resolution of the hematoma when no further bleeding or false aneurysm are present. Prompt removal of access sheaths with 2-4 hours of bed rest following removal can help to decrease the incidence of femoral hematomas.

Larger or rapidly expanding hematomas can lead to hemodynamic compromise and multiple blood transfusions. In this setting, free femoral bleeding secondary to laceration of the femoral artery should be suspected. In such cases, a crossover sheath should be inserted into the contralateral femoral artery and bleeding site localized via angiography. In the case of uncontained bleeding, blood loss can be controlled by inflating a peripheral angioplasty balloon or deploying a graft stent at the site of vessel trauma (Samal \& White, 2002).

$$
<\text { Table 2> }
$$

Retroperitoneal bleeding is a potentially life threatening complication of arterial access, more frequent when the artery is punctured above the inguinal ligament. Such bleeding is typically not evident from the surface, but 
should be suspected when patient develops abdominal or flank pain along with hypotension and decreasing hemoglobin level. CT scans can be used to confirm clinical suspicion, but early recognition is essential in order to expedite application of manual compression and administration of fluids (Figure 4). Older age, female gender, low body surface area, and higher femoral artery puncture are significant risk factors for retroperitoneal hematomas. (Farouque et al., 2005; Sherev et al., 2005) Although there have been some concerns with increased risk with PCI in the glycoprotein IIb/IIIa inhibition era, no associations have been described in large retrospective studies. (Farouque et al., 2005) Most patients can be managed with reversal of anticoagulation, compression of the access site, observation, and volume expansion with or without blood products. When conservative management has failed, tamponading the puncture site via balloon angioplasty from the ipsilateral or contralateral femoral artery can be successfully performed (Samal \& White, 2002).

$$
<\text { Figure } 4>
$$

\subsection{Pseudoaneurysm}

False aneurysms develop when a hematoma maintains continuity with the arterial lumen, resulting in blood flow into and out of the hematoma cavity during systole and diastole. The origin of the nomenclature stems from lack of normal arterial wall structures (media and adventitia) despite the typical aneurysmal appearance. The incidence is between $0.5-2.0 \%$ after diagnostic angiography and has been reported in as many as $7.7 \%$ of patients when coronary or peripheral interventions are performed. (Hessel, Adams, \& Abrams, 1981; Katzenschlager et al., 1995) The principal risk factors for its development are similar to those for hematoma. False aneurysms occur more commonly following low access, where the superficial femoral artery is more likely to be accessed instead of the common femoral artery. This artery is smaller than the common femoral artery, making sheath insertion more traumatic. Furthermore, the lack of underlying bone provides less support for manual compression; too brief a period of manual compression is also a risk factor for its development.(Katzenschlager et al., 1995) Clinically, it is detected as a pulsatile mass with bruit adjacent to the site of femoral access. The diagnosis can be made radiographically demonstrating an aneurysmal structure with a thin neck or sinus tract that connects to the femoral artery. Although angiography and contrast CT can be used to make the diagnosis, Doppler color flow imaging has been shown to be the most effective technique for identification of vascular complications (Figure 4a) (Sheikh et al., 1989). Prompt diagnosis can avoid the catastrophic risk of rupture, which is likely to occur in larger aneurysms $(>3 \mathrm{~cm})$, in the presence of symptoms, large hematoma, or continued growth of the sac.(Kent et al., 1993; Kresowik et al., 1991; Webber, Jang, Gustavson, \& Olin, 2007)

The treatment depends on the size of the false aneurysm and the rate of growth. False aneurysms less than 2-3 $\mathrm{cm}$ in greatest diameter can be managed expectantly and followed on an outpatient basis with serial ultrasound examinations (Johns, Pupa, \& Bailey, 1991; Kent et al., 1993; Kresowik et al., 1991). However, aneurysmal size is not an absolute predictor of thrombosis(Kent et al., 1993); therefore, patients with false aneurysms of any size should be followed closely until thrombosis occurs. Most experts advocate for intervention in symptomatic patients who have a false aneurysm $>2.0 \mathrm{~cm}$ (Webber et al., 2007). Larger aneurysms have traditionally been repaired surgically or through ultrasound-guided compression of the femoral neck without compromising femoral artery flow (Samal \& White, 2002). More recently, percutaneous injection of thrombin (1000 US U/mL) has been demonstrated as an effective method of thrombosis, with up to $96 \%$ primary success rate (Krueger et al., 2005; Webber et al., 2007). Ultrasound guided injection of thrombin can be completed in several minutes, has the advantage of avoiding surgical intervention or the pain associated with ultrasound-guided compression, and can be performed effectively in patients who have received anticoagulation (Figure 5a-d) (Lennox et al., 1999; Pezzullo, Dupuy, \& Cronan, 2000; Taylor et al., 1999). Surgical repair of false aneurysms is reserved for cases which exhibit rapid expansion, infection, or failure of closure via thrombin injection. (Samal, White, Collins, Ramee, \& Jenkins, 2001; Webber et al., 2007)

$$
<\text { Figure 5> }
$$

\subsection{Arteriovenous Fistula}

Arteriovenous Fistulas (AVF) arise when a needle tract crosses both the artery and vein, with subsequent dilation during sheath insertion (Figure 6). They can also arise from on-going bleeding from the puncture site that compresses into an adjacent femoral vein. As such, they are typically caused by low arterial access into the superficial femoral artery because of the anterior-to-posterior relationship of the artery to the superficial femoral vein, as opposed to the side-by-side relationship of the common femoral artery and vein (Kim et al., 1992). Diagnosis is made by the auscultation of a thrill or continuous bruit over the puncture site, and confirmed by contrast CT or Doppler sonography. Prospective follow-up studies in over 10,000 patients undergoing 
transfemoral cardiac catheterization have shown an incidence of almost $1 \%$. Management is usually conservative with close follow-up, as nearly one-third of AVF closed spontaneously within one year(Kelm et al., 2002) Surgical management is reserved for symptomatic patients, high output heart failure, or fistulas that do not close spontaneously within one year(Samal \& White, 2002)

$$
<\text { Figure 6> }
$$

\subsection{Dissection}

Dissection of the femoral and iliac arteries occurs very infrequently, ( $0.42 \%$ of the most current cohorts). (Prasad et al., 2008) It occurs more commonly in iliac arteries with increased atherosclerotic burden, tortuosity, or traumatic sheath placement. Occlusive dissection is a potentially limb and life-threatening complications that can be identified and treated safely upon diagnosis. Cine images of the femoral access site prior to completion of the study are helpful in localizing potential dissections, and should be performed in patients with difficult access or traumatic sheath placement. When detected, removal of the wires and catheters can allow for spontaneous resolution(Samal \& White, 2002) When large, flow limiting dissections occur, angioplasty and stenting have been shown to be a safe and effective method of treatment and surgery can usually be avoided(Scheinert et al., 2000)

\subsection{Thrombosis and Embolism}

Thrombosis typically occurs in female patients with small vessel lumen, peripheral arterial disease, diabetes mellitus, placement of a large diameter catheter or sheath (intraaortic balloon pump), or long catheter dwell-time (Noto et al., 1991; Popma et al., 1993). Patients typically complain of a painful leg with impaired sensation and motor function in the distal extremity. Loss of peripheral pulses and the appearance of a white painful foot can often be found on physical examination. Thrombotic and embolic complications can be avoided with careful, frequent flushing of the arterial sheaths (prevents thrombus formation) and use of anticoagulation during prolonged procedures and intraaortic balloon pump use. Treatment involves percutaneous thrombectomy or thrombolytic therapy in conjunction with vascular surgery consultation (Samal \& White, 2002).

\subsection{Vascular Closure Devices}

Various methods for percutaneous closure of the femoral artery have been explored over the years in order to avoid manual compression and shorten bed rest, two of the biggest sources of dissatisfaction to patients. Although these devices allow for greater comfort and earlier ambulation, their safety and cost effectiveness in comparison to manual compression has not been unequivocally confirmed. Their benefit has been marginal, at best, and many studies have reported increased incidence of vascular complications following PCI (Koreny, Riedmuller, Nikfardjam, Siostrzonek, \& Mullner, 2004; Nikolsky et al., 2004). These reviews, however, were of trials of vascular closure devices in their early years of use. Technological improvements to devices and increased operator experience are likely to contribute to improved efficacy and safety. This was demonstrated in the analysis of the ACUITY trial by Sanborn et al., where interventional or surgical correction or hematoma $\geq 5$ $\mathrm{cm}$ occurred significantly less often in patients undergoing PCI when a vascular closure device was used $(0.4 \%$ versus $0.8 \%, P<0.05$ and $1.9 \%$ versus $2.7 \%, P<0.03$, respectively) (Sanborn et al.). The magnitude of these reductions is very similar to those recently reported from the large Northern New England PCI Registry in which the relative risk reduction in bleeding and vascular complications with bivalirudin and vascular closure device use during PCI was $52 \%$ and $25 \%$, respectively.(Ahmed et al., 2009) Therefore, marked reductions in femoral access complications may be realized with advancement in vascular closure device technology and increased operator experience, along with adjunctive medications that decrease the risk of bleeding.

\subsection{Transradial Approach}

Transradial approach has gained progressive acceptance since its introduction over 20 years ago, largely due to decrease in vascular complications and patient satisfaction with the procedure. The approach has several advantages, in that, the radial artery is not immediately associated with nearby nerves or veins and is easily compressible, allowing for improved hemostasis. Furthermore, the hand receives dual blood supply through the ulnar and radial arteries via the palmar arch. Therefore, any radial artery occlusion (reported in 5-19\%) (Greenwood et al., 2005) is not clinically important in most patients because the hand is perfused by extensive collateral flow between the two arteries. When performed properly, the Allen test is an easy and effective method to assess the adequacy of collateral blood flow into the hand. In patients in whom the Allen test fails, there is an increased incidence of complications and occlusion of flow to the hand.

In a meta-analysis by Agostini et al. in 2004, similar rates of major adverse cardiovascular events with both access routes were observed, with significantly lower rate of entry site complications in the radial access group. 
The advantages are, however, balanced by the higher proportion of procedural failures, $7.2 \%$ versus $2.4 \%$ for femoral access (Agostoni et al., 2004). Data from the National Cardiovascular Data Registry from 2004-2007 has shown that the proportion of radial artery interventions has been increasing steadily. However, they still only constitute $1.3 \%$ of all total procedures performed during that time. Compared with the femoral approach, use of radial PCI in recent data is associated with similar rate of procedural success but lower risk of procedural bleeding(Rao et al., 2008) Increased operator experience, further development of low profile catheters and stents, along with greater patient satisfaction and comfort, fuel the interest in this field.

\section{Conduction Disturbances}

\subsection{Bradyarrhythmia}

Transient bradycardia is a common occurrence in the catheterization laboratory. They were far more frequent in the era of high osmolar ionic contrast agents, but have declined recently due to the widespread use of iso-osmolar, non-ionic contrast material. Prolonged episodes of bradycardia can lead to vagal response with associated hypotension, nausea, sweating, and yawning. This was observed in nearly $3.5 \%$ of patients in one study, $80 \%$ of which developed during access and $16 \%$ during sheath removal (Landau, Lange, Glamann, Willard, \& Hillis, 1994). Treatment of anxiety and pain, along with adequate hydration can help avoid prolonged vagal reactions. Furthermore, hypotension and bradycardia can be one of the first signs of perforation and tamponade, as a vagal response is induced through irritation of the pericardium. Coughing forcefully can help to increase coronary perfusion and restore normal cardiac rhythm. When coughing is unsuccessful, rapid intravenous fluid administration, treatment of underlying pain or anxiety, and 0.5-1 mg of atropine intravenously can help reverse the bradycardia. In cases of complete heart block, temporary pacing through a transvenous pacemaker should be rapidly initiated.

Conduction disturbances also occur, but at a much lower frequency than vagal episodes. Passing of the catheter across the aortic valve will usually cause some ectopy. However, in a patient with pre-existing right bundle branch block, the development of left bundle branch block because of septal scraping can lead to complete heart block and cardiovascular collapse. Conversely, in a patient with a pre-existing left bundle branch block, right heart catheterization and right bundle branch block can cause a similar scenario. As such, the electrocardiogram of every patient should be reviewed prior to procedure by the operator. Minimizing the period of ectopy can help in avoiding these complications.

\subsection{Tachyarrhythmia}

Atrial arrhythmias may occur following irritation of the right atrium by the catheter during right heart catheterization. These arrhythmias usually do not require immediate treatment unless they produce ischemia or hemodynamic instability. The occurrence of ventricular tachycardia and ventricular fibrillation in the current era is related to irritation of the myocardium by the catheter. Identification of ventricular ectopy by trained technicians and engaged operators can help reduce the incidence of these arrhythmias. When a run of ventricular tachycardia is noted, the offending catheter must be pulled back immediately to allow restoration of normal sinus rhythm. Ventricular arrhythmias were more prominent in the era of high osmolar, ionic contrast when intracoronary injection into the right coronary artery caused ventricular dysrhythmia in $1.3 \%$ of patients.(Adams, Fraser, \& Abrams, 1973; Zukerman et al., 1987) The most recent reports, however, place this complication rate at $0.1 \%$ (Chen, Gao, \& Yao, 2008). In patients with acute myocardial infarction, ventricular tachycardia occurred in $4.3 \%$ of the patients with ST- elevation MI during cardiac catheterization in the PAMI trial.(Mehta et al., 2004) Pre-treatment of high risk patients with beta-blockers, or initiation of anitarrhythmic therapy with lidocaine or amiodarone during recurrent episodes should be considered as treatment options. Hemodynamically unstable atrial rhythms or any sustained ventricular tachyarrhythmia should be treated with direct current cardioversion.

\section{Death}

During the last few decades, the incidence of death has progressively declined during left heart catheterization. In the early $1960 \mathrm{~s}, 1 \%$ mortality was observed with diagnostic catheterization, which has decreased to $0.08 \%$ in the 1990s(Braunwald \& Gorlin, 1968; Chandrasekar et al., 2001; Johnson et al., 1989; Kennedy, 1982; Noto et al., 1991) There are a number of baseline variables which contribute to mortality during coronary angiography: presence of multivessel disease, left main coronary artery disease (LMCA), CHF, renal insufficiency and advanced age are the most important of them (Laskey, Boyle, \& Johnson, 1993). In recent years, cardiac catheterization and percutaneous coronary intervention have witnessed new developments, such as stents and potent antiplatelet agents that could affect the overall complication rate.(Chandrasekar et al., 2001) 
Significant LMCA disease increases the risk of dissection during catheter engagement and injection of contrast, which is reported to be around $0.07 \%$ and almost twice higher with percutaneous intervention(Cheng et al., 2008; Eshtehardi et al.) Mortality associated with iatrogenic LMCA dissection is reported around 3\% (Eshtehardi et al.), particularly if undetected. Emergency therapeutic interventions with either coronary artery bypass surgery or percutaneous coronary intervention with stents are required.

Patient with depressed chronic left ventricular function and those with acute MI who are in shock are at the highest risk for mortality.(Anderson et al., 2007; Johnson et al., 1989; Shaw et al., 2002) If frank cardiogenic shock is present or develops during cardiac catheterization, intra-aortic balloon pump and inotropic support may be required.

If PCI is performed in addition to coronary angiography, the incidence of mortality is higher.(Dorros et al., 1983; Shaw et al., 2002) Recent data from the American College of Cardiology-National Cardiovascular Data Registry (ACC-NCDR) published in 2010 have shown that factors which are associated with increased risk of mortality during PCI are cardiogenic shock, increasing age, salvage, urgent or emergency PCI, decreased left ventricular ejection fraction, acute MI, diabetes, chronic renal failure, multivessel disease, prior coronary artery bypass grafts (CABG) and chronic occlusion. Overall, PCI in-hospital mortality was $1.27 \%$, ranging from $0.65 \%$ in elective PCI to 4.81\% in ST- elevation MI patients. (Anderson et al., 2007; Peterson et al.; Shaw et al., 2002)

Patients with aortic stenosis have higher mortality; the VA Cooperative study on Valvular Heart Disease has shown a $0.2 \%$ mortality among 1559 preoperative catheterizations. (Folland et al., 1989) Bartsch et al. have shown a mortality rate $1.1 \%$ in patients with aortic value stenosis requiring left heart catheterization to determine the transvalvular gradient.(Bartsch, Haase, Voelker, Schobel, \& Karsch, 1999)

Patients with history of $\mathrm{CABG}$ who required diagnostic and therapeutic cardiac catheterization are typically older and have generalized atherosclerosis, worse left ventricular function, and require a more lengthy and complex procedure. Varghese et al. have shown that patients with coronary artery bypass undergoing graft PCI have no difference in terms of mortality as compared to patients with CABG undergoing native vessel PCI (Varghese, Samuel, Banerjee, \& Brilakis, 2009)'(Garcia-Tejada et al., 2009).

\section{Myocardial Infarction}

Myocardial damage can occur in different clinical settings: spontaneous, during diagnostic cardiac catheterizations, during percutaneous intervention and during CABG surgery. There have been different thresholds for identifying an infarct in clinical trials: CK-MB $>2$ times the upper limit of normal (ULN) for spontaneous MI; CK-MB $>3$ times the ULN with coronary interventions; and CK-MB $>5-10$ times the ULN for bypass surgery (Alpert, Thygesen, Antman, \& Bassand, 2000). In the late 1970s, the data from the Coronary Artery Surgery Study (CASS) showed a MI rate of $0.25 \%$ for coronary angiography (Davis et al., 1979). In the first, second, and third registries conducted by the Society for Cardiac Angiography, the risk of MI fell progressively, from $0.07 \%$, to $0.06 \%$, to $0.05 \%$ (Johnson et al., 1989; Kennedy, 1982; Noto et al., 1991). The risk of MI during diagnostic catheterization is clearly influenced by patient-related factors that include the extent of CAD $(0.06 \%$ for single vessel disease, $0.08 \%$ for triple-vessel disease, and $0.17 \%$ for left main disease) (Johnson et al., 1989). With improvement in the equipment and operator skill, the use of more potent antithrombotic and antiplatelet agents, better patient preparation with the use of beta blockers and statins and adoption of low osmolar contrast agents, the incidence of myocardial MI during cardiac catheterization has been reduced considerably (Judkin \& Gander, 1974; Pasceri et al., 2004).

Approximately 1.5 million patients undergo PCI in the United States every year (Roger et al.). Depending on local practices and diagnostic criteria used, 5 to $30 \%$ of these patients have evidence of peri-procedural MI.

At the higher estimate, the incidence of these events is similar to the annual rate of major spontaneous MI. The predictors of peri-procedural MI can be broadly categorized as patient-, lesion-, and procedure- related risk factors (Herrmann, 2005). The major risk factors in terms of both frequency and extent, are complex lesions (e.g., the presence of thrombus, stenosis of a saphenous-vein graft, or a type $\mathrm{C}$ lesion), complex procedures (e.g., treatment of multiple lesions or use of rotational atherectomy), and procedural complications (e.g., abrupt vessel closure, side-branch occlusion, distal embolization, or no reflow). (Herrmann, 2005; Mandadi et al., 2004; van Gaal et al., 2009) The occurrence of peri-procedural ischemic symptoms, particularly chest pain at the end of the procedure, or electrocardiographic evidence of ischemia defines the sub-group of patients most likely to have peri-procedural MI (Cai et al., 2007).

Large peri-procedural myocardial MIs are usually due to angiographically visible complications; however, this is generally not the case in the vast majority of patients with elevated biomarker levels after PCI. Cardiac magnetic 
resonance imaging has confirmed two distinct locations for peri-procedural myonecrosis: adjacent to the site of the intervention, where the injury is most likely due to epicardial side-branch occlusion and downstream from the intervention site, where it is most likely due to compromise of the microvascular circulation.

Studies evaluating the relationship between the post-procedural cardiac troponin level and long term mortality, in general, have not excluded patients with acute coronary syndromes (ACS), many of whom had abnormal cardiac biomarker levels at baseline. (Cantor et al., 2002; Cavallini et al., 2005; D. N. Feldman, Minutello, Bergman, Moussa, \& Wong, 2009; Kini et al., 2004; Kizer et al., 2003; Nallamothu et al., 2003; Natarajan et al., 2004; Nienhuis, Ottervanger, Bilo, Dikkeschei, \& Zijlstra, 2008; Testa et al., 2009) Thus, the reported frequency of post-procedural elevations in cardiac troponin has been highly variable, and although some studies showed that the serum concentration of cardiac troponin was an independent predictor of survival, others did not.

It remains uncertain whether a similar amount of damage in different settings has the same prognostic implications. Mahaffey et al. have studied the outcome of peri-procedural MI versus spontaneous MI in a large pool of 16,173 patients from PURSUIT and PARAGON B trials of non-ST- elevation MI. It was clearly evident that patients with peri-procedural or spontaneous MI had significantly higher one and six month mortality. (Mahaffey et al., 2005) A recent analysis from the ACUITY trial was conducted among 7,773 patients with moderate to high risk, non-ST elevation MI who underwent PCI. (Prasad et al., 2009) Peri-procedural and spontaneous MIs during follow-up developed in $6.0 \%$ and $2.6 \%$ of the cohort, respectively. After adjustment for differences in baseline and procedural characteristics, spontaneous MI was a powerful independent predictor of an increased risk of death, whereas peri-procedural MI was not significantly associated with an increased risk of death. Similar observation was made among patients with diabetes and stable CAD in Bypass Angioplasty Revascularization Investigation 2 Diabetes (BARI 2D) trial. (Chaitman et al., 2009)

Taken together, contemporary studies indicate that spontaneous MI is a powerful predictor of mortality. Peri-procedural MI, although frequent, is a marker of atherosclerosis burden and procedural complexity, but in most cases, it does not have important independent prognostic significance in stable CAD or in non-ST-elevation MI. Although large peri-procedural infarcts may affect prognosis, they rarely occur in the absence of procedural complications or in patients with normal baseline cardiac troponin levels.

\section{Cerebrovascular Complications}

Although the overall incidence of stroke after left heart catheterization or percutaneous intervention is low, it is the most debilitating complication and is associated with a high rate of morbidity and mortality (Table 3, Figure 7) (Akkerhuis et al., 2001; Fuchs et al., 2002; Lazar et al., 1995; Wong, Minutello, \& Hong, 2005). Early experience showed an incidence as high as $0.23 \%$ in the 1973 study of Adams and others (Adams et al., 1973), compared with the $0.07 \%$ incidence for the more recent diagnostic catheterization data included in the Society for Cardiac Angiography-registries (Johnson et al., 1989; Kennedy, 1982).

$$
\begin{aligned}
& <\text { Figure } 7> \\
& <\text { Table 3> }
\end{aligned}
$$

The risk of stroke, as expected, is somewhat higher with coronary intervention, because of use of guiding catheters, multiple equipment exchanges in the aortic root, aggressive anticoagulation and longer procedure times. In 20,697 patients who underwent PCI in a large-volume center, stroke occurred in 0.44\%(Dukkipati et al., 2004). Multivariable analysis has shown that occurrence of stroke was associated with diabetes, hypertension, prior stroke and renal failure and was an independent predictor of in-hospital death (Hamon et al., 2008). Patients who suffered a stroke had undergone longer cardiac catheterization procedures, received more contrast, were more likely to have had the procedure for urgent reasons, and to have intra-aortic balloon counter pulsation.(Stone et al., 1997) Possible explanations for this latter characteristic include the greater propensity for hemodynamic compromise in these patients, which may increase the risk of ischemic stroke. Indeed, scraping of aortic plaque occurs in $>50 \%$ of PCI cases and more frequently with larger catheters (Keeley \& Grines, 1998).

Cerebral micro-embolism is thought to be the main mechanism of peri-procedural ischemic stroke occurring with PCI. This finding is supported by transcranial doppler studies performed during cardiac catheterization, which show the systematic occurrence of cerebral micro-emboli.(Bladin et al., 1998; Hamon et al., 2006; Leclercq et al., 2001) Air embolism, thrombus formation in the catheter or its surface, or dislocation of aortic atheroma during manipulation and passage of catheters within the aorta are the main sources of embolic material causing ischemic stroke during cardiac catheterization or PCI. As expected, patients with CAD more frequently have severe atheroma in the descending aorta and aortic arch than patients without CAD (Khoury, Gottlieb, Stern, \& Keren, 1997). 
In addition to the aortic root, embolic material may also originate in the cardiac chambers, thrombotic coronary arteries, or the surface of cardiac valves. One should avoid placing the pigtail catheter in the left ventricle in patients with suspected aneurysm or recent MI, since either condition may be associated with potentially dislodgeable mural thrombus.

Peri-procedural strokes associated with invasive procedures are predominantly (80\%) attributable to embolic material that lodges in cerebral arteries. However, given the increasingly aggressive antithrombotic environment used in PCI, especially in ACS, cerebral hemorrhages are also encountered. This means that ischemic or hemorrhagic mechanisms have to be documented before any treatment can be initiated.

\section{Dissection and Perforation of Great Vessels}

Perforation of the cardiac chambers, coronary arteries or intrathoracic great vessels is fortunately a rare event in diagnostic catheterization. The incidence of catheter-induced ascending aorta dissection is reported around $0.04 \%$ of cases (Gomez-Moreno et al., 2006). The incidence of coronary artery dissection is reported around $30 \%$ with balloon angioplasty (Figures 8-10).(Cowley, Dorros, Kelsey, Van Raden, \& Detre, 1984; Huber, Mooney, Madison, \& Mooney, 1991)

$<$ Figure 8, 9,10>

In recent registries the incidence of coronary artery perforation has been reported to occur in $0.3-0.6 \%$ of patients undergoing PCI. (Cowley et al., 1984; Dippel et al., 2001; Ellis et al., 1994; Gruberg et al., 2000) With the use of hydrophilic guidewires, platelet IIb/IIIa receptor blockers, and more aggressive atherectomy technologies, the incidence of coronary perforation may be higher. Some perforations, particularly those limited to deep injury to the vessel wall with localized perivascular contrast staining, can simply be observed. But such patients are at risk for delayed tamponade during the several hours following the procedure and must be monitored carefully. In contrast, free perforation may lead to development of frank tamponade within seconds to minutes, particularly when the patient is fully anticoagulated. Immediate measures should be used to seal the perforation with inflation of balloon proximal to the perforation. If after 10-15 minutes or development of ischemia, the extravasation of contrast persists, graft stents need to be utilized to seal the arterial rupture. In parallel, pericardiocentesis should be considered to provide the time necessary to seal the perforation. Overall, the reported incidence of required emergency surgery following diagnostic angiography is $0.05 \%$, and $0.3 \%$ following therapeutic procedures (Chandrasekar et al., 2001; Loubeyre et al., 1999). However, once coronary artery perforation is diagnosed, the reported incidence of emergency surgery requiring pericardial window, bypass surgery or coronary artery ligation is as high as $24-40 \%$ (Table 4 ).

\section{$<$ Table 4>}

Perforation of the great vessels (aorta or pulmonary artery) is extremely rare. Ascending aortic dissection can also result from vigorous use of a guiding catheter or extension from proximal coronary dissection.

Right heart catheterization can cause cardiac perforation; it is usually accompanied by bradycardia and hypotension owing to vasovagal stimulation. As blood accumulates in the pericardium, the cardiac silhouette may enlarge and the normal pulsation of the heart borders on fluoroscopy will become blunted. If the patient is hemodynamically compromised, immediate pericardiocentesis is should be performed via the subxiphoid approach. Once pericardiocentesis has stabilized the situation, the operator must decide whether or not emergency surgery will be needed to over sew the site of perforation. Most perforations, in fact, will seal spontaneously, so that surgery is unnecessary.

\section{Other Complications}

\subsection{Hypotension}

Reduction in arterial blood pressure is one of the most common problems seen during catheterization. This reduction is the final common manifestation of a variety of conditions including the following: (a) hypovolemia, owing to inadequate hydration before procedure, or excessive contrast-induced diuresis; (b) reduction in cardiac output, tamponade, arrhythmia or valvular regurgitation; or (c) inappropriate systemic arteriolar vasodilatation, due to vasodepressor response to contrast or (d) potential bleeding from retroperitoneal hemorrhage.

Low filling pressures mandate rapid volume administration, whereas low filling pressure combined with inappropriate bradycardia indicates a vasovagal reaction and atropine should be given in addition to fluid resuscitation. High filling pressures, however, suggest primary cardiac dysfunction and should prompt consideration of ischemia, tamponade, or sudden onset of valvular regurgitation. Such patients should be supported empirically by inotropic agents, vasopressors or circulatory support devices. 
Patients with hypotension and normal or high cardiac output measured through saturation Swan-Ganz catheters are more likely to have an allergic reaction to contrast and may require vasopressor support, steroids and histamine blockers.

\subsection{Hypoglycemia}

Diabetic patients who are required to fast before procedure may develop hypoglycemia; special attention should be given to these patients and finger-stick blood glucose should be monitored closely before and during the procedure. If any signs of hypoglycemia, including anxiety, or lethargy develop, prompt action should be taken to administer intravenous glucose.

\subsection{Respiratory insufficiency}

Respiratory insufficiency can occur from a variety of reasons, including CHF with pulmonary edema, pre-existing lung disease, and allergic reaction or over-sedation. Immediate assessment of patient's condition is required and therapeutic measures should be taken based on the presumed etiology.

\section{Conclusion}

Cardiac catheterization is a relatively safe procedure with few complications. Although advances in medical management and equipment design have added further significant reductions to the already low incidence of complications, operator awareness and appropriateness of response remain as the most important predictors to adverse outcomes. With each coronary angiography the potential benefit of the procedure should be weighed against the established risk factors with the well-defined morbidity and mortality. The widespread use and availability of angiography will likely fuel further advances in percutaneous modalities that may increase patient comfort while simultaneously reducing complications further.

\section{References}

Acetylcysteine for prevention of renal outcomes in patients undergoing coronary and peripheral vascular angiography: main results from the randomized Acetylcysteine for Contrast-induced nephropathy Trial (ACT). (2011). [Comparative Study Meta-Analysis Randomized Controlled Trial Research Support, Non-U.S. Gov't]. Circulation, 124 (11), 1250-1259. http://dx.doi.org/10.1161/CIRCULATIONAHA.111.038943

Adams, D. F., Fraser, D. B., \& Abrams, H. L. (1973). The complications of coronary arteriography. Circulation, 48 (3), 609-618.

Agostoni, P., Biondi-Zoccai, G. G., de Benedictis, M. L., et al. (2004). Radial versus femoral approach for percutaneous coronary diagnostic and interventional procedures; Systematic overview and meta-analysis of randomized trials. J Am Coll Cardiol, 44 (2), 349-356.

Ahmed, B., Piper, W. D., Malenka, D., et al. (2009). Significantly improved vascular complications among women undergoing percutaneous coronary intervention: a report from the Northern New England Percutaneous Coronary Intervention Registry. Circ Cardiovasc Interv, 2 (5), 423-429. http://dx.doi.org/10.1161/CIRCINTERVENTIONS.109.860494

Akkerhuis, K. M., Deckers, J. W., Lincoff, A. M., et al. (2001). Risk of stroke associated with abciximab among patients undergoing percutaneous coronary intervention. Jama, 286 (1), 78-82.

Alpert, J. S., Thygesen, K., Antman, E., et al. (2000). Myocardial infarction redefined--a consensus document of The Joint European Society of Cardiology/American College of Cardiology Committee for the redefinition of myocardial infarction. J Am Coll Cardiol, 36 (3), 959-969.

Anderson, H. V., Shaw, R. E., Brindis, R. G., et al. (2007). Risk-adjusted mortality analysis of percutaneous coronary interventions by American College of Cardiology/American Heart Association guidelines recommendations. Am J Cardiol, 99 (2), 189-196.

Applegate, R. J., Sacrinty, M. T., Kutcher, M. A., et al. (2006). Propensity score analysis of vascular complications after diagnostic cardiac catheterization and percutaneous coronary intervention 1998-2003. Catheter Cardiovasc Interv, 67 (4), 556-562. http://dx.doi.org/10.1002/ccd.20677

Applegate, R. J., Sacrinty, M. T., Kutcher, M. A., et al. (2008). Trends in vascular complications after diagnostic cardiac catheterization and percutaneous coronary intervention via the femoral artery, 1998 to 2007. JACC Cardiovasc Interv, 1 (3), 317-326. http://dx.doi.org/10.1016/j.jcin.2008.03.013

Aspelin, P., Aubry, P., Fransson, S. G., et al. (2003). Nephrotoxic effects in high-risk patients undergoing angiography. N Engl J Med, 348 (6), 491-499. 
Babu, S. C., Piccorelli, G. O., Shah, P. M., et al. (1989). Incidence and results of arterial complications among 16,350 patients undergoing cardiac catheterization. J Vasc Surg, 10 (2), 113-116.

Baddour, L. M., Bettmann, M. A., Bolger, A. F., et al. (2004). Nonvalvular cardiovascular device-related infections. Clin Infect Dis, 38 (8), 1128-1130.

Bader, B. D., Berger, E. D., Heede, M. B., Silberbaur, I., Duda, S., Risler, T., \& Erley, C. M. (2004). What is the best hydration regimen to prevent contrast media-induced nephrotoxicity? Clin Nephrol, 62 (1), 1-7.

Barrett, B. J. \& Carlisle, E. J. (1993). Metaanalysis of the relative nephrotoxicity of high- and low-osmolality iodinated contrast media. Radiology, 188 (1), 171-178.

Barrett, B. J., Parfrey, P. S., Vavasour, H. M., et al. (1992). A comparison of nonionic, low-osmolality radiocontrast agents with ionic, high-osmolality agents during cardiac catheterization. $N$ Engl J Med, 326 (7), 431-436. http://dx.doi.org/10.1056/NEJM199202133260702

Bartholomew, B. A., Harjai, K. J., Dukkipati, S., et al. (2004). Impact of nephropathy after percutaneous coronary intervention and a method for risk stratification. Am J Cardiol, 93 (12), 1515-1519.

Bartsch, B., Haase, K. K., Voelker, W., et al. (1999). Risk of invasive diagnosis with retrograde catheterization of the left ventricle in patients with acquired aortic valve stenosis. Z Kardiol, 88 (4), 255-260.

Bashore, T. M., Bates, E. R., Berger, P. B., et al. (2001). American College of Cardiology/Society for Cardiac Angiography and Interventions Clinical Expert Consensus Document on cardiac catheterization laboratory standards. A report of the American College of Cardiology Task Force on Clinical Expert Consensus Documents. J Am Coll Cardiol, 37 (8), 2170-2214.

Bashore, T. M., \& Gehrig, T. (2003). Cholesterol emboli after invasive cardiac procedures. J Am Coll Cardiol, $42(2), 217-218$.

Bertrand, M. E., Esplugas, E., Piessens, J., et al. (2000). Influence of a nonionic, iso-osmolar contrast medium (iodixanol) versus an ionic, low-osmolar contrast medium (ioxaglate) on major adverse cardiac events in patients undergoing percutaneous transluminal coronary angioplasty: A multicenter, randomized, double-blind study. Visipaque in Percutaneous Transluminal Coronary Angioplasty [VIP] Trial Investigators. Circulation, 101 (2), 131-136.

Birck, R., Krzossok, S., Markowetz, F., et al. (2003). Acetylcysteine for prevention of contrast nephropathy: meta-analysis. Lancet, 362 (9384), 598-603. http://dx.doi.org/ 10.1016/S0140-6736(03)14189-X

Bladin, C. F., Bingham, L., Grigg, L., et al. (1998). Transcranial Doppler detection of microemboli during percutaneous transluminal coronary angioplasty. Stroke, 29 (11), 2367-2370.

Brar, S. S., Shen, A. Y., Jorgensen, M. B., et al. (2008). Sodium bicarbonate vs sodium chloride for the prevention of contrast medium-induced nephropathy in patients undergoing coronary angiography: a randomized trial. Jama, 300 (9), 1038-1046.

Braunwald, E. \& Gorlin, R. (1968). Cooperative study on cardiac catheterization. Total population studied, procedures employed, and incidence of complications. Circulation, 37 (5 Suppl), III8-16.

Brieger, D. B., Mak, K. H., Kottke-Marchant, K., et al. (1998). Heparin-induced thrombocytopenia. J Am Coll Cardiol, 31 (7), 1449-1459.

Briguori, C., Airoldi, F., D'Andrea, D., et al. (2007). Renal Insufficiency Following Contrast Media Administration Trial (REMEDIAL): a randomized comparison of 3 preventive strategies. Circulation, 115 (10), 1211-1217. http://dx.doi.org/10.1161/CIRCULATIONAHA.106.687152

Bush, W. H. \& Swanson, D. P. (1991). Acute reactions to intravascular contrast media: types, risk factors, recognition, and specific treatment. AJR Am J Roentgenol, 157 (6), 1153-1161.

Butler, R. \& Webster, M. W. (2002). Meralgia paresthetica: an unusual complication of cardiac catheterization via the femoral artery. Catheter Cardiovasc Interv, 56 (1), 69-71. http://dx.doi.org/10.1002/ccd.10149

Cai, Q., Skelding, K. A., Armstrong, A. T. Jr., et al. (2007). Predictors of periprocedural creatine kinase-myocardial band elevation complicating elective percutaneous coronary intervention. Am J Cardiol, 99 (5), 616-620. http://dx.doi.org/10.1016/j.amjcard.2006.09.108

Campbell, K. R., Mahaffey, K. W., Lewis, B. E., et al. (2000). Bivalirudin in patients with heparin-induced thrombocytopenia undergoing percutaneous coronary intervention. J Invasive Cardiol, 12 Suppl F, 14F-19. 
Cantor, W. J., Newby, L. K., Christenson, R. H., et al. (2002). Prognostic significance of elevated troponin I after percutaneous coronary intervention. J Am Coll Cardiol, 39 (11), 1738-1744.

Cavallini, C., Savonitto, S., Violini, R., et al. (2005). Impact of the elevation of biochemical markers of myocardial damage on long-term mortality after percutaneous coronary intervention: results of the CK-MB and PCI study. Eur Heart J, 26 (15), 1494-1498.

Chaitman, B. R., Hardison, R. M., Adler, D., et al. (2009). The Bypass Angioplasty Revascularization Investigation 2 Diabetes randomized trial of different treatment strategies in type 2 diabetes mellitus with stable ischemic heart disease: impact of treatment strategy on cardiac mortality and myocardial infarction. Circulation, 120 (25), 2529-2540. http://dx.doi.org/10.1161/CIRCULATIONAHA.109.913111

Chambers, C. E., Eisenhauer, M. D., McNicol, L. B., et al. (2006). Infection control guidelines for the cardiac catheterization laboratory: society guidelines revisited. Catheter Cardiovasc Interv, 67 (1), 78-86. http://dx.doi.org/10.1002/ccd.20589

Chandrasekar, B., Doucet, S., Bilodeau, L., et al. (2001). Complications of cardiac catheterization in the current era: a single-center experience. Catheter Cardiovasc Interv, 52 (3), 289-295. http://dx.doi.org/10.1002/ccd.1067

Chen, J., Gao, L., \& Yao, M. (2008). Ventricular arrhythmia onset during diagnostic coronary angiography with a 5F or 4F universal catheter. Rev Esp Cardiol, 61(10), 1092-1095.

Cheng, C. I., Wu, C. J., Hsieh, Y. K., et al. (2008). Percutaneous coronary intervention for iatrogenic left main coronary artery dissection. Int J Cardiol, 126 (2), 177-182. http://dx.doi.org/10.1016/j.ijcard.2007.03.125

Cigarroa, R. G., Lange, R. A., Williams, R. H., et al. (1989). Dosing of contrast material to prevent contrast nephropathy in patients with renal disease. Am J Med, 86 (6 Pt 1), 649-652.

Cooper, C. L. \& Miller, A. (1999). Infectious complications related to the use of the angio-seal hemostatic puncture closure device. Catheter Cardiovasc Interv, 48 (3), 301-303.

Cowley, M. J., Dorros, G., Kelsey, S. F., et al. (1984). Acute coronary events associated with percutaneous transluminal coronary angioplasty. Am J Cardiol, 53 (12), 12C-16C.

Coyle, L. C., Rodriguez, A., Jeschke, R. E., et al. (2006). Acetylcysteine In Diabetes (AID): a randomized study of acetylcysteine for the prevention of contrast nephropathy in diabetics. Am Heart J, 151 (5), 1032 e1039-1012. http://dx.doi.org/10.1016/j.ahj.2006.02.002

Davis, K., Kennedy, J. W., Kemp, H. G. Jr., et al. (1979). Complications of coronary arteriography from the Collaborative Study of Coronary Artery Surgery (CASS). Circulation, 59 (6), 1105-1112.

Dewachter, P., Mouton-Faivre, C., \& Emala, C. W. (2009). Anaphylaxis and anesthesia: controversies and new insights. Anesthesiology, 111 (5), 1141-1150.

Diaz-Sandoval, L. J., Kosowsky, B. D., \& Losordo, D. W. (2002). Acetylcysteine to prevent angiography-related renal tissue injury (the APART trial). Am J Cardiol, 89 (3), 356-358.

Dippel, E. J., Kereiakes, D. J., Tramuta, D. A., et al. (2001). Coronary perforation during percutaneous coronary intervention in the era of abciximab platelet glycoprotein IIb/IIIa blockade: an algorithm for percutaneous management. Catheter Cardiovasc Interv, 52 (3), 279-286. http://dx.doi.org/10.1002/ccd.1065

Dorros, G., Cowley, M. J., Simpson, J., et al. (1983). Percutaneous transluminal coronary angioplasty: report of complications from the National Heart, Lung, and Blood Institute PTCA Registry. Circulation, 67 (4), 723-730.

Doyle, B. J., Ting, H. H., Bell, M. R., et al. (2008). Major femoral bleeding complications after percutaneous coronary intervention: incidence, predictors, and impact on long-term survival among 17,901 patients treated at the Mayo Clinic from 1994 to 2005. JACC Cardiovasc Interv, 1 (2), 202-209. http://dx.doi.org/10.1016/j.jcin.2007.12.006

Dukkipati, S., O'Neill, W. W., Harjai, K. J., et al. (2004). Characteristics of cerebrovascular accidents after percutaneous coronary interventions. J Am Coll Cardiol, 43 (7), 1161-1167.

Elinav, E., Chajek-Shaul, T., \& Stern, M. (2002). Improvement in cholesterol emboli syndrome after iloprost therapy. BMJ, 324 (7332), 268-269.

Ellis, S. G., Ajluni, S., Arnold, A. Z., et al. (1994). Increased coronary perforation in the new device era. Incidence, classification, management, and outcome. Circulation, 90 (6), 2725-2730. 
Eshtehardi, P., Adorjan, P., Togni, M., et al. (2010). Iatrogenic left main coronary artery dissection: incidence, classification, management, and long-term follow-up. Am Heart J, 159 (6), 1147-1153. http://dx.doi.org/10.1016/j.ahj.2010.03.012

Farouque, H. M., Tremmel, J. A., Raissi Shabari, F., et al. (2005). Risk factors for the development of retroperitoneal hematoma after percutaneous coronary intervention in the era of glycoprotein $\mathrm{IIb} / \mathrm{IIIa}$ inhibitors and vascular closure devices. J Am Coll Cardiol, 45 (3), 363-368. http://dx.doi.org/10.1016/j.jacc.2004.10.042

Feldman, D. N., Minutello, R. M., Bergman, G., et al. (2009). Relation of troponin I levels following nonemergent percutaneous coronary intervention to short- and long-term outcomes. Am J Cardiol, 104 (9), 1210-1215.

Feldman, T., Moss, J., Teplinsky, K., et al. (1990). Cardiac catheterization in the patient with history of allergy to local anesthetics. Cathet Cardiovasc Diagn, 20 (3), 165-167.

Finder, R. L. \& Moore, P. A. (2002). Adverse drug reactions to local anesthesia. Dent Clin North Am, 46 (4), 747-757, x.

Folland, E. D., Oprian, C., Giacomini, J., et al. (1989). Complications of cardiac catheterization and angiography in patients with valvular heart disease. VA Cooperative Study on Valvular Heart Disease. Cathet Cardiovasc Diagn, 17 (1), 15-21.

Freed, K. S., Leder, R. A., Alexander, C., et al. (2001). Breakthrough adverse reactions to low-osmolar contrast media after steroid premedication. AJR Am J Roentgenol, 176 (6), 1389-1392.

Freeman, R. V., O'Donnell, M., Share, D., et al. (2002). Nephropathy requiring dialysis after percutaneous coronary intervention and the critical role of an adjusted contrast dose. Am J Cardiol, 90 (10), 1068-1073.

From, A. M., Bartholmai, B. J., Williams, A. W., et al. (2008). Sodium bicarbonate is associated with an increased incidence of contrast nephropathy: a retrospective cohort study of 7977 patients at mayo clinic. Clin J Am Soc Nephrol, 3 (1), 10-18. http://dx.doi.org/10.2215/CJN.03100707

Fuchs, S., Stabile, E., Kinnaird, T. D., et al. (2002). Stroke complicating percutaneous coronary interventions: incidence, predictors, and prognostic implications. Circulation, 106 (1), 86-91.

Fukumoto, Y., Tsutsui, H., Tsuchihashi, M., et al. (2003). The incidence and risk factors of cholesterol embolization syndrome, a complication of cardiac catheterization: a prospective study. J Am Coll Cardiol, 42 (2), 211-216.

Fung, J. W., Szeto, C. C., Chan, W. W., et al. (2004). Effect of N-acetylcysteine for prevention of contrast nephropathy in patients with moderate to severe renal insufficiency: a randomized trial. Am J Kidney Dis, 43 (5), 801-808.

Gami, A. S., \& Garovic, V. D. (2004). Contrast nephropathy after coronary angiography. Mayo Clin Proc, 79 (2), 211-219.

Garcia-Tejada, J., Velazquez, M., Hernandez, F., et al. (2009). Percutaneous revascularization of grafts versus native coronary arteries in postcoronary artery bypass graft patients. Angiology, 60 (1), 60-66. http://dx.doi.org/10.1177/0003319708317335

Garrett, P. D., Eckart, R. E., Bauch, T. D., et al. (2005). Fluoroscopic localization of the femoral head as a landmark for common femoral artery cannulation. Catheter Cardiovasc Interv, 65 (2), 205-207. http://dx.doi.org/10.1002/ccd.20373

Gomez-Moreno, S., Sabate, M., Jimenez-Quevedo, P., et al. (2006). Iatrogenic dissection of the ascending aorta following heart catheterisation: incidence, management and outcome. EuroIntervention, 2 (2), 197-202.

Goss, J. E., Chambers, C. E., \& Heupler, F. A. Jr. (1995). Systemic anaphylactoid reactions to iodinated contrast media during cardiac catheterization procedures: guidelines for prevention, diagnosis, and treatment. Laboratory Performance Standards Committee of the Society for Cardiac Angiography and Interventions. Cathet Cardiovasc Diagn, 34 (2), 99-104; discussion 105.

Graziani, G., Santostasi, S., Angelini, C., et al. (2001). Corticosteroids in cholesterol emboli syndrome. Nephron, 87 (4), 371-373.

Greenberger, P. A., Halwig, J. M., Patterson, R., et al. (1986). Emergency administration of radiocontrast media in high-risk patients. $J$ Allergy Clin Immunol, 77 (4), 630-634. 
Greenwood, M. J., Della-Siega, A. J., Fretz, E. B., et al. (2005). Vascular communications of the hand in patients being considered for transradial coronary angiography: is the Allen's test accurate? J Am Coll Cardiol, 46 (11), 2013-2017. http://dx.doi.org/10.1016/j.jacc.2005.07.058

Gruberg, L., Pinnow, E., Flood, R., et al. (2000). Incidence, management, and outcome of coronary artery perforation during percutaneous coronary intervention. Am J Cardiol, 86 (6), 680-682, A688.

Gupta, B. K., Savage, M. P., \& Brest, A. N. (1995). Acute myocardial infarction during coronary angioplasty associated with heparin-induced thrombocytopenia. Cathet Cardiovasc Diagn, 35 (1), 42-46.

Hamon, M., Baron, J. C., \& Viader, F. (2008). Periprocedural stroke and cardiac catheterization. [Case ReportsReview]. Circulation, 118 (6), 678-683. http://dx.doi.org/10.1161/CIRCULATIONAHA.108.784504

Hamon, M., Gomes, S., Oppenheim, C., et al. (2006). Cerebral microembolism during cardiac catheterization and risk of acute brain injury: a prospective diffusion-weighted magnetic resonance imaging study. Stroke, 37 (8), 2035-2038. http://dx.doi.org/10.1161/01.STR.0000231641.55843.49

Herrmann, J. (2005). Peri-procedural myocardial injury: 2005 update. Eur Heart J, 26 (23), 2493-2519. http://dx.doi.org/10.1093/eurheartj/ehi455

Hessel, S. J., Adams, D. F., \& Abrams, H. L. (1981). Complications of angiography. Radiology, 138 (2), 273-281.

Hildreth, E. A. (1987). Anaphylactoid reactions to iodinated contrast media. Hosp Pract (Off Ed), 22 (5A), 77-85, 89-90, 95.

Hourigan, L. A., Walters, D. L., Keck, S. A., et al. (2002). Heparin-induced thrombocytopenia: a common complication in cardiac transplant recipients. J Heart Lung Transplant, 21 (12), 1283-1289.

Huber, M. S., Mooney, J. F., Madison, J., et al. (1991). Use of a morphologic classification to predict clinical outcome after dissection from coronary angioplasty. Am J Cardiol, 68 (5), 467-471.

Jacobi, J. A., Schussler, J. M., \& Johnson, K. B. (2009). Routine femoral head fluoroscopy to reduce complications in coronary catheterization. Proc (Bayl Univ Med Cent), 22 (1), 7-8.

James, M. T., Ghali, W. A., Knudtson, M. L., et al. (2011). Associations between acute kidney injury and cardiovascular and renal outcomes after coronary angiography. Circulation, 123 (4), 409-416. http://dx.doi.org/10.1161/CIRCULATIONAHA.110.970160

Jang, I. K., \& Hursting, M. J. (2005). When heparins promote thrombosis: review of heparin-induced thrombocytopenia. Circulation, 111 (20), 2671-2683. http://dx.doi.org/10.1161/CIRCULATIONAHA.104.5185 63

Jo, S. H., Youn, T. J., Koo, B. K., et al. (2006). Renal toxicity evaluation and comparison between visipaque (iodixanol) and hexabrix (ioxaglate) in patients with renal insufficiency undergoing coronary angiography: the RECOVER study: a randomized controlled trial. $J$ Am Coll Cardiol, 48 (5), 924-930. http://dx.doi.org/10.1016/j.jacc.2006.06.047

Johns, J. P., Pupa, L. E. Jr., \& Bailey, S. R. (1991). Spontaneous thrombosis of iatrogenic femoral artery pseudoaneurysms: documentation with color Doppler and two-dimensional ultrasonography. J Vasc Surg, 14 (1), 24-29.

Johnson, L. W., Lozner, E. C., Johnson, S., et al. (1989). Coronary arteriography 1984-1987: a report of the Registry of the Society for Cardiac Angiography and Interventions. I. Results and complications. Cathet Cardiovasc Diagn, 17 (1), 5-10.

Judkin, M. P. \& Gander, M. P. (1974). Prevention of complications of coronary arteriography. Circulation, 49 (4), 599-602.

Kappers-Klunne, M. C., Boon, D. M., Hop, W. C., et al. (1997). Heparin-induced thrombocytopenia and thrombosis: a prospective analysis of the incidence in patients with heart and cerebrovascular diseases. $\mathrm{Br} J$ Haematol, 96 (3), 442-446.

Katzenschlager, R., Ugurluoglu, A., Ahmadi, A., et al. (1995). Incidence of pseudoaneurysm after diagnostic and therapeutic angiography. Radiology, 195 (2), 463-466.

Keeley, E. C. \& Grines, C. L. (1998). Scraping of aortic debris by coronary guiding catheters: a prospective evaluation of 1,000 cases. $J$ Am Coll Cardiol, 32 (7), 1861-1865. 
Kelm, M., Perings, S. M., Jax, T., et al. (2002). Incidence and clinical outcome of iatrogenic femoral arteriovenous fistulas: implications for risk stratification and treatment. J Am Coll Cardiol, 40 (2), 291-297.

Kennedy, J. W. (1982). Complications associated with cardiac catheterization and angiography. Cathet Cardiovasc Diagn, 8 (1), 5-11.

Kent, K. C., McArdle, C. R., Kennedy, B., et al. (1993). A prospective study of the clinical outcome of femoral pseudoaneurysms and arteriovenous fistulas induced by arterial puncture. J Vasc Surg, 17 (1), 125-131; discussion 131-123.

Khoury, Z., Gottlieb, S., Stern, S., et al. (1997). Frequency and distribution of atherosclerotic plaques in the thoracic aorta as determined by transesophageal echocardiography in patients with coronary artery disease. $\mathrm{Am} J$ Cardiol, 79 (1), 23-27.]

Kim, D., Orron, D. E., Skillman, J. J., et al. (1992). Role of superficial femoral artery puncture in the development of pseudoaneurysm and arteriovenous fistula complicating percutaneous transfemoral cardiac catheterization. Cathet Cardiovasc Diagn, 25 (2), 91-97.

Kini, A. S., Lee, P., Marmur, J. D., et al. (2004). Correlation of postpercutaneous coronary intervention creatine kinase-MB and troponin I elevation in predicting mid-term mortality. Am J Cardiol, 93 (1), 18-23.

Kinnaird, T. D., Stabile, E., Mintz, G. S., et al. (2003). Incidence, predictors, and prognostic implications of bleeding and blood transfusion following percutaneous coronary interventions. Am J Cardiol, 92 (8), 930-935.

Kizer, J. R., Muttrej, M. R., Matthai, W. H., et al. (2003). Role of cardiac troponin T in the long-term risk stratification of patients undergoing percutaneous coronary intervention. Eur Heart J, 24 (14), 1314-1322.

Ko, W., Lazenby, W. D., Zelano, J. A., et al. (1992). Effects of shaving methods and intraoperative irrigation on suppurative mediastinitis after bypass operations. Ann Thorac Surg, 53 (2), 301-305.

Koreny, M., Riedmuller, E., Nikfardjam, M., et al. (2004). Arterial puncture closing devices compared with standard manual compression after cardiac catheterization: systematic review and meta-analysis. Jama, 291 (3), 350-357.

Krasuski, R. A., Beard, B. M., Geoghagan, J. D., et al. (2003). Optimal timing of hydration to erase contrast-associated nephropathy: the OTHER CAN study. J Invasive Cardiol, 15 (12), 699-702.

Kresowik, T. F., Khoury, M. D., Miller, B. V., et al. (1991). A prospective study of the incidence and natural history of femoral vascular complications after percutaneous transluminal coronary angioplasty. J Vasc Surg, 13 (2), 328-333; discussion 333-325.

Kronzon, I., \& Saric, M. (2010). Cholesterol embolization syndrome. Circulation, 122 (6), 631-641. http://dx.doi.org/10.1161/CIRCULATIONAHA.109.886465

Krueger, K., Zaehringer, M., Strohe, D., et al. (2005). Postcatheterization pseudoaneurysm: results of US-guided percutaneous thrombin injection in 240 patients. Radiology, 236 (3), 1104-1110. http://dx.doi.org/10.1148/radiol.2363040736

Landau, C., Lange, R. A., Glamann, D. B., et al. (1994). Vasovagal reactions in the cardiac catheterization laboratory. Am J Cardiol, 73 (1), 95-97.

Lang, D. M., Alpern, M. B., Visintainer, P. F., et al. (1991). Increased risk for anaphylactoid reaction from contrast media in patients on beta-adrenergic blockers or with asthma. Ann Intern Med, 115 (4), 270-276.

Laskey, W., Boyle, J., \& Johnson, L. W. (1993). Multivariable model for prediction of risk of significant complication during diagnostic cardiac catheterization. The Registry Committee of the Society for Cardiac Angiography \& Interventions. Cathet Cardiovasc Diagn, 30 (3), 185-190.

Laslett, L. J. \& Sabin, A. (1989). Wearing of caps and masks not necessary during cardiac catheterization. Cathet Cardiovasc Diagn, 17 (3), 158-160.

Lautin, E. M., Freeman, N. J., Schoenfeld, A. H., et al. (1991). Radiocontrast-associated renal dysfunction: a comparison of lower-osmolality and conventional high-osmolality contrast media. AJR Am J Roentgenol, 157 (1), 59-65.

Lazar, J. M., Uretsky, B. F., Denys, B. G., et al. (1995). Predisposing risk factors and natural history of acute neurologic complications of left-sided cardiac catheterization. Am J Cardiol, 75 (15), 1056-1060.

Leclercq, F., Kassnasrallah, S., Cesari, J. B., et al. (2001). Transcranial Doppler detection of cerebral microemboli during left heart catheterization. Cerebrovasc Dis, 12 (1), 59-65. 
Lennox, A. F., Griffin, M. B., Cheshire, N. J., et al. (1999). Treatment of an iatrogenic femoral artery pseudoaneurysm with percutaneous duplex-guided injection of thrombin. Circulation, 100 (6), e39-41.

Lewis, B. E., Matthai, W. H. Jr., Cohen, M., et al. (2002). Argatroban anticoagulation during percutaneous coronary intervention in patients with heparin-induced thrombocytopenia. Catheter Cardiovasc Interv, 57 (2), 177-184. http://dx.doi.org/10.1002/ccd.10276

Loubeyre, C., Morice, M. C., Berzin, B., et al. (1999). Emergency coronary artery bypass surgery following coronary angioplasty and stenting: results of a French multicenter registry. Catheter Cardiovasc Interv, 47 (4), 441-448.

Mahaffey, K. W., Lewis, B. E., Wildermann, N. M., et al. (2003). The anticoagulant therapy with bivalirudin to assist in the performance of percutaneous coronary intervention in patients with heparin-induced thrombocytopenia (ATBAT) study: main results. J Invasive Cardiol, 15 (11), 611-616.

Mahaffey, K. W., Roe, M. T., Kilaru, R., et al. (2005). Characterization of myocardial infarction as an end point in two large trials of acute coronary syndromes. Am $J$ Cardiol, 95 (12), 1404-1408. http://dx.doi.org/10.1016/j.amjcard.2005.02.005

Maioli, M., Toso, A., Leoncini, M., et al. (2008). Sodium bicarbonate versus saline for the prevention of contrast-induced nephropathy in patients with renal dysfunction undergoing coronary angiography or intervention. $J$ Am Coll Cardiol, 52(8), 599-604. http://dx.doi.org/10.1016/j.jacc.2008.05.026

Mandadi, V. R., DeVoe, M. C., Ambrose, J. A., et al. (2004). Predictors of troponin elevation after percutaneous coronary intervention. Am J Cardiol, 93 (6), 747-750. http://dx.doi.org/10.1016/j.amjcard.2003.11.070

Mandak, J. S., Blankenship, J. C., Gardner, L. H., et al. (1998). Modifiable risk factors for vascular access site complications in the IMPACT II Trial of angioplasty with versus without eptifibatide. Integrilin to Minimize Platelet Aggregation and Coronary Thrombosis. J Am Coll Cardiol, 31 (7), 1518-1524.

Marenzi, G., Assanelli, E., Campodonico, J., et al. (2009). Contrast volume during primary percutaneous coronary intervention and subsequent contrast-induced nephropathy and mortality. Ann Intern Med, 150 (3), 170-177.

Marenzi, G., Assanelli, E., Marana, I., et al. (2006). N-acetylcysteine and contrast-induced nephropathy in primary angioplasty. $N$ Engl J Med, 354 (26), 2773-2782. http://dx.doi.org/10.1056/NEJMoa054209

Marenzi, G., Marana, I., Lauri, G., et al. (2003). The prevention of radiocontrast-agent-induced nephropathy by hemofiltration. $N$ Engl J Med, 349 (14), 1333-1340. http://dx.doi.org/10.1056/NEJMoa023204

Matthai, W. H. Jr., Kussmaul, W. G. 3rd, Krol, J., et al. (1994). A comparison of low- with high-osmolality contrast agents in cardiac angiography. Identification of criteria for selective use. Circulation, 89 (1), 291-301.

McCready, R. A., Siderys, H., Pittman, J. N., et al. (1991). Septic complications after cardiac catheterization and percutaneous transluminal coronary angioplasty. $J$ Vasc Surg, 14 (2), 170-174. http://dx.doi.org/10.1067/mva.1991.29134

McCullough, P. A., Bertrand, M. E., Brinker, J. A., et al. (2006). A meta-analysis of the renal safety of isosmolar iodixanol compared with low-osmolar contrast media. $J$ Am Coll Cardiol, 48(4), 692-699. http://dx.doi.org/10.1016/j.jacc.2006.02.073

McCullough, P. A., Wolyn, R., Rocher, L. L., et al. (1997). Acute renal failure after coronary intervention: incidence, risk factors, and relationship to mortality. Am J Med, 103 (5), 368-375.

Mehran, R., Aymong, E. D., Nikolsky, E., et al. (2004). A simple risk score for prediction of contrast-induced nephropathy after percutaneous coronary intervention: development and initial validation. $J$ Am Coll Cardiol, 44 (7), 1393-1399.

Mehta, R. H., Harjai, K. J., Grines, L., et al. (2004). Sustained ventricular tachycardia or fibrillation in the cardiac catheterization laboratory among patients receiving primary percutaneous coronary intervention: incidence, predictors, and outcomes. $J$ Am Coll Cardiol, 43 (10), 1765-1772. http://dx.doi.org/10.1016/j.jacc.2003.09.072

Merten, G. J., Burgess, W. P., Gray, L. V., et al. (2004). Prevention of contrast-induced nephropathy with sodium bicarbonate: a randomized controlled trial. Jama, 291 (19), 2328-2334.

Metz, D., Meyer, P., Touati, C., et al. (1997). Comparison of 6F with 7F and 8F guiding catheters for elective coronary angioplasty: results of a prospective, multicenter, randomized trial. Am Heart J, 134 (1), 131-137. 
Mueller, C., Buerkle, G., Buettner, H. J., et al. (2002). Prevention of contrast media-associated nephropathy: randomized comparison of 2 hydration regimens in 1620 patients undergoing coronary angioplasty. Arch Intern Med, 162 (3), 329-336.

Munoz, P., Blanco, J. R., Rodriguez-Creixems, M., et al. (2001). Bloodstream infections after invasive nonsurgical cardiologic procedures. Arch Intern Med, 161 (17), 2110-2115.

Murphy, S. W., Barrett, B. J., \& Parfrey, P. S. (2000). Contrast nephropathy. J Am Soc Nephrol, 11 (1), 177-182. Myers, G. E. \& Bloom, F. L. (1981). Cimetidine (Tagamet) combined with steroids and H1 antihistamines for the prevention of serious radiographic contrast material reactions. Cathet Cardiovasc Diagn, 7 (1), 65-69.

Nallamothu, B. K., Chetcuti, S., Mukherjee, D., et al. (2003). Prognostic implication of troponin I elevation after percutaneous coronary intervention. Am J Cardiol, 91(10), 1272-1274.

Natarajan, M. K., Kreatsoulas, C., Velianou, J. L., et al. (2004). Incidence, predictors, and clinical significance of troponin-I elevation without creatine kinase elevation following percutaneous coronary interventions. Am J Cardiol, 93 (6), 750-753. http://dx.doi.org/10.1016/j.amjcard.2003.11.069

Nayak, K. R., White, A. A., Cavendish, J. J., et al. (2009). Anaphylactoid reactions to radiocontrast agents: prevention and treatment in the cardiac catheterization laboratory. J Invasive Cardiol, 21 (10), 548-551.

Nienhuis, M. B., Ottervanger, J. P., Bilo, H. J., et al. (2008). Prognostic value of troponin after elective percutaneous coronary intervention: A meta-analysis. Catheter Cardiovasc Interv, 71 (3), 318-324. http://dx.doi.org/10.1002/ccd.21345

Nikolsky, E., Mehran, R., Dangas, G., et al. (2007). Development and validation of a prognostic risk score for major bleeding in patients undergoing percutaneous coronary intervention via the femoral approach. Eur Heart J, 28 (16), 1936-1945. http://dx.doi.org/10.1093/eurheartj/ehm194

Nikolsky, E., Mehran, R., Halkin, A., et al. (2004). Vascular complications associated with arteriotomy closure devices in patients undergoing percutaneous coronary procedures: a meta-analysis. $J$ Am Coll Cardiol, 44 (6), 1200-1209.

Noto, T. J., Jr., Johnson, L. W., Krone, R., et al. (1991). Cardiac catheterization 1990: a report of the Registry of the Society for Cardiac Angiography and Interventions (SCA\&I). Cathet Cardiovasc Diagn, 24 (2), 75-83.

O'Grady, N. P., Alexander, M., Dellinger, E. P., et al. (2002). Guidelines for the prevention of intravascular catheter-related infections. Centers for Disease Control and Prevention. MMWR Recomm Rep, 51 (RR-10), 1-29.

Omoigui, N. A., Califf, R. M., Pieper, K., et al. (1995). Peripheral vascular complications in the Coronary Angioplasty Versus Excisional Atherectomy Trial (CAVEAT-I). J Am Coll Cardiol, 26 (4), 922-930.

Oweida, S. W., Roubin, G. S., Smith, R. B., 3rd, et al. (1990). Postcatheterization vascular complications associated with percutaneous transluminal coronary angioplasty. J Vasc Surg, 12 (3), 310-315.

Pasceri, V., Patti, G., Nusca, A., et al. (2004). Randomized trial of atorvastatin for reduction of myocardial damage during coronary intervention: results from the ARMYDA (Atorvastatin for Reduction of MYocardial Damage during Angioplasty) study. Circulation, $110 \quad$ 674-678. http://dx.doi.org/10.1161/01.CIR.0000137828.06205.87

Peterson, E. D., Dai, D., DeLong, E. R., et al. (2010). Contemporary mortality risk prediction for percutaneous coronary intervention: results from 588,398 procedures in the National Cardiovascular Data Registry. $J$ Am Coll Cardiol, 55 (18), 1923-1932. http://dx.doi.org/10.1016/j.jacc.2010.02.005

Pezzullo, J. A., Dupuy, D. E., \& Cronan, J. J. (2000). Percutaneous injection of thrombin for the treatment of pseudoaneurysms after catheterization: an alternative to sonographically guided compression. $A J R A m J$ Roentgenol, 175 (4), 1035-1040.

Polanczyk, C. A., Rohde, L. E., Goldman, L., et al. (2001). Right heart catheterization and cardiac complications in patients undergoing noncardiac surgery: an observational study. Jama, 286 (3), 309-314.

Popma, J. J., Satler, L. F., Pichard, A. D., et al. (1993). Vascular complications after balloon and new device angioplasty. Circulation, 88 (4 Pt 1), 1569-1578.

Prasad, A., Compton, P. A., Roesle, M., et al. (2008). Incidence and Treatment of Arterial Access Dissections Occurring during Cardiac Catheterization. $J$ Interv Cardiol, 21 (1), 61-66. http://dx.doi.org/10.1111/j.1540-8183.2007.00309.x 
Prasad, A., Gersh, B. J., Bertrand, M. E., et al. (2009). Prognostic significance of periprocedural versus spontaneously occurring myocardial infarction after percutaneous coronary intervention in patients with acute coronary syndromes: an analysis from the ACUITY (Acute Catheterization and Urgent Intervention Triage Strategy) trial. J Am Coll Cardiol, 54 (5), 477-486. http://dx.doi.org/10.1016/j.jacc.2009.03.063

Ramirez, G., O'Neill, W. M., Jr., Lambert, R., et al. (1978). Cholesterol embolization: a complication of angiography. Arch Intern Med, 138 (9), 1430-1432.

Ramsdale, D. R., Aziz, S., Newall, N., et al. (2004). Bacteremia following complex percutaneous coronary intervention. J Invasive Cardiol, 16 (11), 632-634.

Rao, S. V., Ou, F. S., Wang, T. Y., et al. (2008). Trends in the prevalence and outcomes of radial and femoral approaches to percutaneous coronary intervention: a report from the National Cardiovascular Data Registry. JACC Cardiovasc Interv, 1 (4), 379-386. http://dx.doi.org/10.1016/j.jcin.2008.05.007

Recio-Mayoral, A., Chaparro, M., Prado, B., et al. (2007). The reno-protective effect of hydration with sodium bicarbonate plus $\mathrm{N}$-acetylcysteine in patients undergoing emergency percutaneous coronary intervention: the RENO Study. J Am Coll Cardiol, 49 (12), 1283-1288. http://dx.doi.org/10.1016/j.jacc.2006.11.034

Rihal, C. S., Textor, S. C., Grill, D. E., et al. (2002). Incidence and prognostic importance of acute renal failure after percutaneous coronary intervention. Circulation, 105 (19), 2259-2264.

Roger, V. L., Go, A. S., Lloyd-Jones, D. M., et al. (2010). Heart disease and stroke statistics--2011 update: a report from the American Heart Association. Circulation, 123 (4), e18-e209. http://dx.doi.org/10.1161/CIR.0b013e3182009701

Rudnick, M. R., Berns, J. S., Cohen, R. M., et al. (1997). Contrast media-associated nephrotoxicity. Semin Nephrol, 17 (1), 15-26.

Rudnick, M. R., Goldfarb, S., Wexler, L., et al. (1995). Nephrotoxicity of ionic and nonionic contrast media in 1196 patients: a randomized trial. The Iohexol Cooperative Study. Kidney Int, 47 (1), 254-261.

Saklayen, M. G., Gupta, S., Suryaprasad, A., et al. (1997). Incidence of atheroembolic renal failure after coronary angiography. A prospective study. Angiology, 48 (7), 609-613.

Samal, A. K., \& White, C. J. (2002). Percutaneous management of access site complications. Catheter Cardiovasc Interv, 57 (1), 12-23. http://dx.doi.org/10.1002/ccd.10179

Samal, A. K., White, C. J., Collins, T. J., et al. (2001). Treatment of femoral artery pseudoaneurysm with percutaneous thrombin injection. Catheter Cardiovasc Interv, 53 (2), 259-263. http://dx.doi.org/10.1002/ccd.1161

Sanborn, T. A., Ebrahimi, R., Manoukian, S. V., et al. (2010). Impact of femoral vascular closure devices and antithrombotic therapy on access site bleeding in acute coronary syndromes: The Acute Catheterization and Urgent Intervention Triage Strategy (ACUITY) trial. Circ Cardiovasc Interv, 3 (1), 57-62. http://dx.doi.org/10.1161/CIRCINTERVENTIONS.109.896704

Scheinert, D., Ludwig, J., Steinkamp, H. J., et al. (2000). Treatment of catheter-induced iliac artery injuries with self-expanding endografts. J Endovasc Ther, 7 (3), 213-220.

Schrader, R., Esch, I., Ensslen, R., et al. (1999). A randomized trial comparing the impact of a nonionic (Iomeprol) versus an ionic (Ioxaglate) low osmolar contrast medium on abrupt vessel closure and ischemic complications after coronary angioplasty. J Am Coll Cardiol, 33 (2), 395-402.

Shammas, R. L., Reeves, W. C., \& Mehta, P. M. (1993). Deep venous thrombosis and pulmonary embolism following cardiac catheterization. Cathet Cardiovasc Diagn, 30 (3), 223-226.

Shaw, R. E., Anderson, H. V., Brindis, R. G., et al. (2002). Development of a risk adjustment mortality model using the American College of Cardiology-National Cardiovascular Data Registry (ACC-NCDR) experience: 1998-2000. J Am Coll Cardiol, 39 (7), 1104-1112.

Sheikh, K. H., Adams, D. B., McCann, R., et al. (1989). Utility of Doppler color flow imaging for identification of femoral arterial complications of cardiac catheterization. Am Heart J, 117 (3), 623-628.

Sherev, D. A., Shaw, R. E., \& Brent, B. N. (2005). Angiographic predictors of femoral access site complications: implication for planned percutaneous coronary intervention. Catheter Cardiovasc Interv, 65 (2), 196-202. http://dx.doi.org/10.1002/ccd.20354 
Solomon, R. (2005). The role of osmolality in the incidence of contrast-induced nephropathy: a systematic review of angiographic contrast media in high risk patients. Kidney Int, 68 (5), 2256-2263. http://dx.doi.org/10.1111/j.1523-1755.2005.00684.x

Solomon, R., Werner, C., Mann, D., et al. (1994). Effects of saline, mannitol, and furosemide to prevent acute decreases in renal function induced by radiocontrast agents. $N$ Engl J Med, 331 (21), 1416-1420. http://dx.doi.org/10.1056/NEJM199411243312104

Solomon, R. J., Natarajan, M. K., Doucet, S., et al. (2007). Cardiac Angiography in Renally Impaired Patients (CARE) study: a randomized double-blind trial of contrast-induced nephropathy in patients with chronic kidney disease. Circulation, 115 (25), 3189-3196. http://dx.doi.org/10.1161/CIRCULATIONAHA.106.671644

Spargias, K., Alexopoulos, E., Kyrzopoulos, S., et al. (2004). Ascorbic acid prevents contrast-mediated nephropathy in patients with renal dysfunction undergoing coronary angiography or intervention. Circulation, 110 (18), 2837-2842. http://dx.doi.org/10.1161/01.CIR.0000146396.19081.73

Steinberg, E. P., Moore, R. D., Powe, N. R., et al. (1992). Safety and cost effectiveness of high-osmolality as compared with low-osmolality contrast material in patients undergoing cardiac angiography. $N$ Engl J Med, 326 (7), 425-430. http://dx.doi.org/10.1056/NEJM199202133260701

Stone, G. W., Marsalese, D., Brodie, B. R., et al. (1997). A prospective, randomized evaluation of prophylactic intraaortic balloon counterpulsation in high risk patients with acute myocardial infarction treated with primary angioplasty. Second Primary Angioplasty in Myocardial Infarction (PAMI-II) Trial Investigators. $J$ Am Coll Cardiol, 29 (7), 1459-1467.

Stone, G. W., McCullough, P. A., Tumlin, J. A., et al. (2003). Fenoldopam mesylate for the prevention of contrast-induced nephropathy: a randomized controlled trial. Jama, 290 (17), 2284-2291.

Taliercio, C. P., Vlietstra, R. E., Ilstrup, D. M., et al. (1991). A randomized comparison of the nephrotoxicity of iopamidol and diatrizoate in high risk patients undergoing cardiac angiography. J Am Coll Cardiol, 17 (2), 384-390.

Talley, J. D., Mauldin, P. D., \& Becker, E. R. (1995). A prospective randomized trial comparing the benefits and limitations of $6 \mathrm{Fr}$ and $8 \mathrm{Fr}$ guiding catheters in elective coronary angioplasty: clinical, procedural, angiographic, and economic end points. J Interv Cardiol, 8 (4), 345-353.

Taylor, B. S., Rhee, R. Y., Muluk, S., et al. (1999). Thrombin injection versus compression of femoral artery pseudoaneurysms. J Vasc Surg, 30 (6), 1052-1059.

Tepel, M., van der Giet, M., Schwarzfeld, C., et al. (2000). Prevention of radiographic-contrast-agent-induced reductions in renal function by acetylcysteine. $N$ Engl $J$ Med, 343 (3), 180-184. http://dx.doi.org/10.1056/NEJM200007203430304

Testa, L., Van Gaal, W. J., Biondi Zoccai, G. G., et al. (2009). Myocardial infarction after percutaneous coronary intervention: a meta-analysis of troponin elevation applying the new universal definition. QJM, 102 (6), 369-378. http://dx.doi.org/10.1093/qjmed/hcp005

Turi, Z. G. (2005). Optimizing vascular access: routine femoral angiography keeps the vascular complication away. Catheter Cardiovasc Interv, 65 (2), 203-204. http://dx.doi.org/10.1002/ccd.20412

van Gaal, W. J., Ponnuthurai, F. A., Selvanayagam, J., et al. (2009). The Syntax score predicts peri-procedural myocardial necrosis during percutaneous coronary intervention. Int $J$ Cardiol, 135 (1), 60-65. http://dx.doi.org/10.1016/j.ijcard.2008.03.033

Varghese, I., Samuel, J., Banerjee, S., et al. (2009). Comparison of percutaneous coronary intervention in native coronary arteries vs. bypass grafts in patients with prior coronary artery bypass graft surgery. Cardiovasc Revasc Med, 10 (2), 103-109. http://dx.doi.org/10.1016/j.carrev.2008.12.002

Vogt, B., Ferrari, P., Schonholzer, C., et al. (2001). Prophylactic hemodialysis after radiocontrast media in patients with renal insufficiency is potentially harmful. Am J Med, 111 (9), 692-698.

Webb, J. G., Pate, G. E., Humphries, K. H., et al. (2004). A randomized controlled trial of intravenous $\mathrm{N}$-acetylcysteine for the prevention of contrast-induced nephropathy after cardiac catheterization: lack of effect. Am Heart J, 148 (3), 422-429. http://dx.doi.org/10.1016/j.ahj.2004.03.041

Webber, G. W., Jang, J., Gustavson, S., et al. (2007). Contemporary management of postcatheterization pseudoaneurysms. Circulation, 115 (20), 2666-2674. http://dx.doi.org/10.1161/CIRCULATIONAHA.106.6819 73 
Weisbord, S. D. \& Palevsky, P. M. (2008). Prevention of contrast-induced nephropathy with volume expansion. Clin J Am Soc Nephrol, 3(1), 273-280. http://dx.doi.org/10.2215/CJN.02580607

Wiener, R. S. \& Ong, L. S. (1989). Local infection after percutaneous transluminal coronary angioplasty: relation to early repuncture of ipsilateral femoral artery. Cathet Cardiovasc Diagn, 16 (3), 180-181.

Wittbrodt, E. T., \& Spinler, S. A. (1994). Prevention of anaphylactoid reactions in high-risk patients receiving radiographic contrast media. Ann Pharmacother, 28 (2), 236-241.

Wong, S. C., Minutello, R., \& Hong, M. K. (2005). Neurological complications following percutaneous coronary interventions (a report from the 2000-2001 New York State Angioplasty Registry). Am J Cardiol, 96 (9), 1248-1250. http://dx.doi.org/10.1016/j.amjcard.2005.06.065

Woolfson, R. G. \& Lachmann, H. (1998). Improvement in renal cholesterol emboli syndrome after simvastatin. Lancet, 351 (9112), 1331-1332. http://dx.doi.org/10.1016/S0140-6736(05)79058-9

Wyman, R. M., Safian, R. D., Portway, V., Skillman, J. J., McKay, R. G., \& Baim, D. S. (1988). Current complications of diagnostic and therapeutic cardiac catheterization. J Am Coll Cardiol, 12 (6), 1400-1406.

Zoungas, S., Ninomiya, T., Huxley, R., et al. (2009). Systematic review: sodium bicarbonate treatment regimens for the prevention of contrast-induced nephropathy. Ann Intern Med, 151 (9), 631-638.

Zukerman, L. S., Friehling, T. D., Wolf, N. M., et al. (1987). Effect of calcium-binding additives on ventricular fibrillation and repolarization changes during coronary angiography. J Am Coll Cardiol, 10 (6), 1249-1253.

Table 1. Specific recommendation for pre-medication regimens. Adapted from the American College of Radiology guidelines (Amreican College of Radiology, 2010). Note that use of H2 blockers is not supported by the current guidelines.

\begin{tabular}{|l|r|}
\hline Elective Pre-Medication & 1. $\begin{array}{l}\text { Prednisone } 50 \mathrm{mg} \text { by mouth at } 13 \text { hours, } 7 \text { hours, and } 1 \\
\text { hour before contrast media injection } \\
\text { Diphenhydramine } 50 \mathrm{mg} \text { intravenous, intramuscular, or } \\
\text { by mouth } 1 \text { hour before contrast medium injection }\end{array}$ \\
\hline Emergency Pre-Medication & 1. $\begin{array}{l}\text { Methylprednisolone } 40 \mathrm{mg} \text { or hydrocortisone sodium } \\
\text { succinate } 200 \mathrm{mg} \text { intravenously every } 4 \text { hours until } \\
\text { contrast study required plus diphenhydramine } 50 \mathrm{mg}\end{array}$ \\
intravenous 1 hour prior to contrast injection \\
2. $\begin{array}{l}\text { Dexamethasone sodium sulfate } 7.5 \mathrm{mg} \text { or betamethasone } \\
6.0 \mathrm{mg} \text { every } 4 \text { hours until contrast study. Must be done } \\
\text { in patients with known allergy to methylprednisolone, } \\
\text { aspirin, or nonsteroidal anti-inflammatory drugs, } \\
\text { especially if asthmatic. Also diphenhydramine } 50 \mathrm{mg}\end{array}$ \\
intravenous 1 hour prior to contrast injection. \\
Omit steroids entirely and give diphenhydramine $50 \mathrm{mg}$ \\
intravenous.
\end{tabular}

Table 2. Changing incidence of major femoral bleeding and blood transfusions after PCI. $\left({ }^{*} \mathrm{p}<0.005\right.$ versus 2000-2005)

\begin{tabular}{|lccc|}
\hline & $\begin{array}{l}\mathbf{1 9 9 4 - 1 9 9 5} \\
(\mathbf{n}=\mathbf{2 , 4 4 1 )}\end{array}$ & $\begin{array}{c}\mathbf{1 9 9 6 - 1 9 9 9} \\
\mathbf{( n = 6 , 2 0 7})\end{array}$ & $\begin{array}{c}\mathbf{2 0 0 0 - 2 0 0 5} \\
\mathbf{( n = 9 , 2 5 3 )}\end{array}$ \\
\hline Femoral Hematoma & $172(7.0 \%)^{*}$ & $236(3.8 \%)^{*}$ & $257(2.8 \%)$ \\
\hline Femoral Bleed & $60(2.5 \%)^{*}$ & $76(1.2 \%)^{*}$ & $54(0.6 \%)$ \\
\hline Retroperitoneal Bleed & $20(0.8 \%)^{*}$ & $19(0.3 \%)$ & $26(0.3 \%)$ \\
\hline Blood Transfusion & $207(8.5 \%)^{*}$ & $482(7.8 \%)^{*}$ & $516(5.6 \%)$ \\
\hline \multicolumn{1}{|c|}{$\mathbf{1}$ to 2 Units } & $98(4.0 \%)$ & $288(4.6 \%)^{*}$ & $347(3.8 \%)$ \\
\hline 3 + Units & $109(4.5 \%)^{*}$ & $194(3.1 \%)^{*}$ & $169(1.8 \%)$ \\
\hline
\end{tabular}


Table 3. Incidence of peri-procedural stroke in PCI registries(Hamon, Baron, \& Viader, 2008)

\begin{tabular}{|c|c|c|c|c|}
\hline Reference & No. Patients & No. & Percentage & $95 \% \mathrm{CI}$ \\
\hline \multicolumn{5}{|l|}{ Lazar et al., 1995} \\
\hline Total & 6465 & 27 & 0.42 & $0.27-0.60$ \\
\hline Ischemic & & NA & NA & NA \\
\hline Hemorrhagic & & NA & NA & NA \\
\hline Uncertain & & NA & NA & NA \\
\hline \multicolumn{5}{|l|}{ Akkerhuis et al., 2001} \\
\hline Total & 8555 & 31 & 0.37 & $0.24-0.51$ \\
\hline Ischemic & & 19 & 0.22 & $0.13-0.34$ \\
\hline Hemorrhagic & & 12 & 1.4 & $0.07-0.24$ \\
\hline Uncertain & & 1 & 0.01 & $0.00-0.06$ \\
\hline \multicolumn{5}{|l|}{ Fuchs et al., 2002} \\
\hline Total & 9662 & 43 & 0.44 & $0.32-0.6$ \\
\hline Ischemic & & 21 & 0.22 & $0.13-0.33$ \\
\hline Hemorrhagic & & 20 & 0.21 & $0.13-0.32$ \\
\hline Uncertain & & 2 & 0.01 & $0.00-0.07$ \\
\hline \multicolumn{5}{|l|}{ Dukkipati et al., 2004} \\
\hline Total & 20679 & 92 & 0.44 & $0.36-0.54$ \\
\hline Ischemic & & 43 & 0.21 & $0.15-0.28$ \\
\hline Hemorrhagic & & 13 & 0.06 & $0.03-0.10$ \\
\hline Uncertain & & 36 & 0.17 & $0.12-0.24$ \\
\hline \multicolumn{5}{|l|}{ Wong et al., 2005} \\
\hline Total & 76903 & 140 & 0.18 & $0.15-0.21$ \\
\hline Ischemic & & NA & NA & NA \\
\hline Hemorrhagic & & NA & NA & NA \\
\hline Uncertain & & NA & NA & NA \\
\hline
\end{tabular}

Table 4. Incidence of coronary artery perforation with in-hospital complications (Nair \& Roguin, 2006)

\begin{tabular}{|l|c|c|c|c|c|}
\hline Reference & Patients & Incidence & CABG & MI & Death \\
\hline Bittl et al., 1993 & 764 & $3 \%$ & 34.7 & 4.3 & 9 \\
\hline Ajluni et al., 1994 & 8932 & $0.40 \%$ & 37 & 26 & 5.6 \\
\hline Holmes et al., 1994 & 2759 & $1.30 \%$ & 36.1 & 16.7 & 4.8 \\
\hline Ellis., 1994 & 12900 & $0.50 \%$ & 24 & 19 & 0 \\
\hline Cohen et al., 1996 & 2953 & $0.70 \%$ & 41 & 45.5 & 9 \\
\hline Gruberg et al., 2000 & 30746 & $0.29 \%$ & 39 & 34 & 10 \\
\hline Dippel., 2001 & 6214 & $0.58 \%$ & 22 & NA & 11 \\
\hline Gunning et al., 2002 & 6245 & $0.80 \%$ & 39 & 29 & 42 \\
\hline Fejka et al., 2002 & 25697 & $0.12 \%$ & 39 & 29 & 42 \\
\hline Stankovic et al., 2004 & 5728 & $1.47 \%$ & 13 & 27 & 8 \\
\hline Witzke et al., 2004 & 12658 & $0.30 \%$ & 5 & 18 & 2.5 \\
\hline Ramana et al., 2005 & 4886 & $0.50 \%$ & 0 & 20 & 8 \\
\hline
\end{tabular}




\section{Figure legend}

Figure 1 Multivariable CIN risk score (Mehran et al., 2004)

Figure 2 Any vascular complications by procedure and closure method. CATH - diagnostic cardiac catheterization; MC - manual compression; PCI - percutaneous coronary intervention; VCD - vascular closure device (Applegate et al., 2008)

Figure 3 (a) Fluoroscopy of the femoral head utilizing forceps to note the position of the inferior border of the femoral head on the patient's skin. (b) Correct placement of the sheath in the common femoral artery. (c) Correct placement of the sheath in relation to the femoral head, with the arterial access incorrectly placed in the superficial femoral artery due to the anatomic variant of a high bifurcation. (d) Correct placement of the sheath in relation to the femoral head with a low hypogastric artery causing incorrect arterial placement in the external iliac artery. (e) Low sheath placement in the profunda femoris artery. (f) High sheath placement in the external iliac artery (Jacobi et al., 2009).

Figure 4 Retroperitoneal bleeding following cardiac catheterization via right femoral access

Figure 5 Duplex ultrasound image of pseudoaneurysm, demonstrating arterial flow through a long, narrow neck arising from defect in femoral artery and turbulent color flow into cavity (a). With color flow removed, exact position of needle tip can be identified at all times during procedure, because a small amount of echogenic thrombus forms at needle tip when thrombin comes into contact with blood, helping to guide needle placement (b). With needle in position, color flow during injection of thrombin confirms acute development of thrombus within sac (c). Power Doppler image of patent native fem- oral vessels (CFA indicates common femoral artery; SFA, superficial femoral artery; and PFA, profunda femoris artery) and absence of flow after successful thrombin injection into pseudoaneurysm cavity (d) (Lennox et al., 1999).

Figure $6 \mathrm{AVF}$ result when needle tract crossing both artery and vein is dilated and catheterized. $\mathrm{V}=$ vein, $\mathrm{A}=$ artery(Kim et al., 1992)

Figure 7 Pooled relative risk (random effects) of mortality after stroke in PCI or in patients with non STelevation MI

Figure 8 Angiogram of right coronary artery before (a) and after perforation (b).

Figure 9 Angiogram of right coronary artery prior to intervention (a), after balloon angioplasty (b) and dissection (c).

Figure 10 Angiogram of the left coronary system (a). Dissection of the left circumflex artery with guidewire catheter (b) with subsequent extension in to the left anterior descending artery (c).

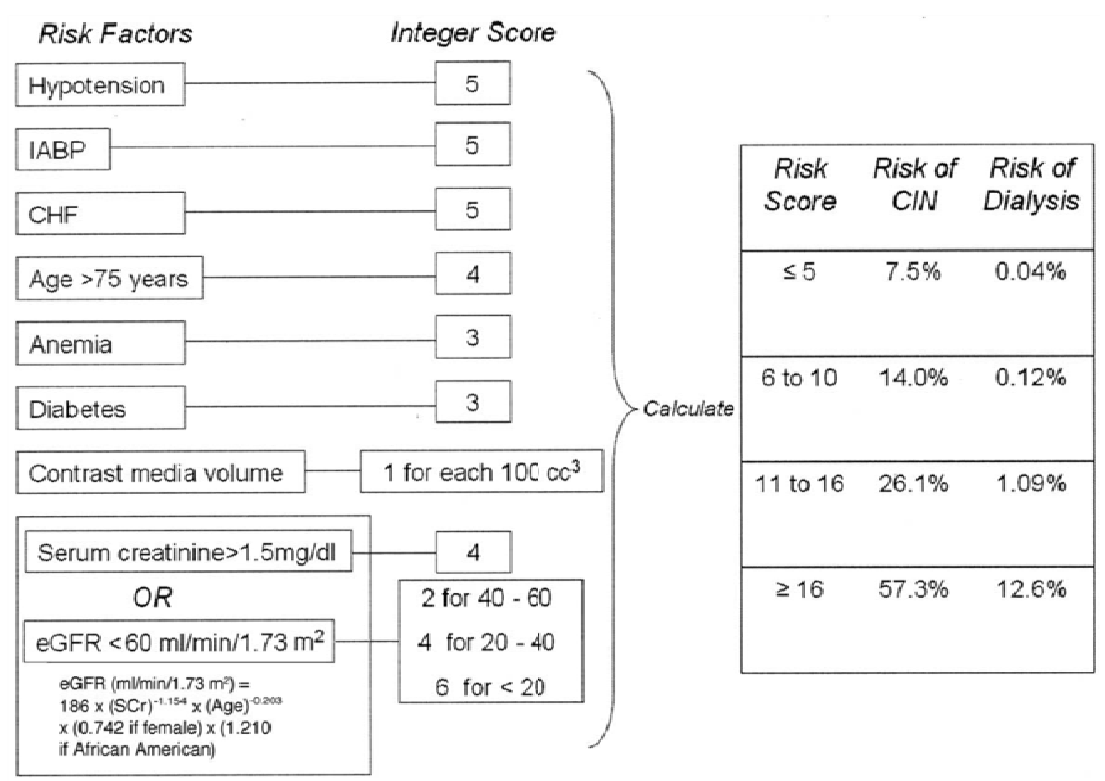

Figure 1. Multivariable CIN risk score (Mehran et al., 2004) 


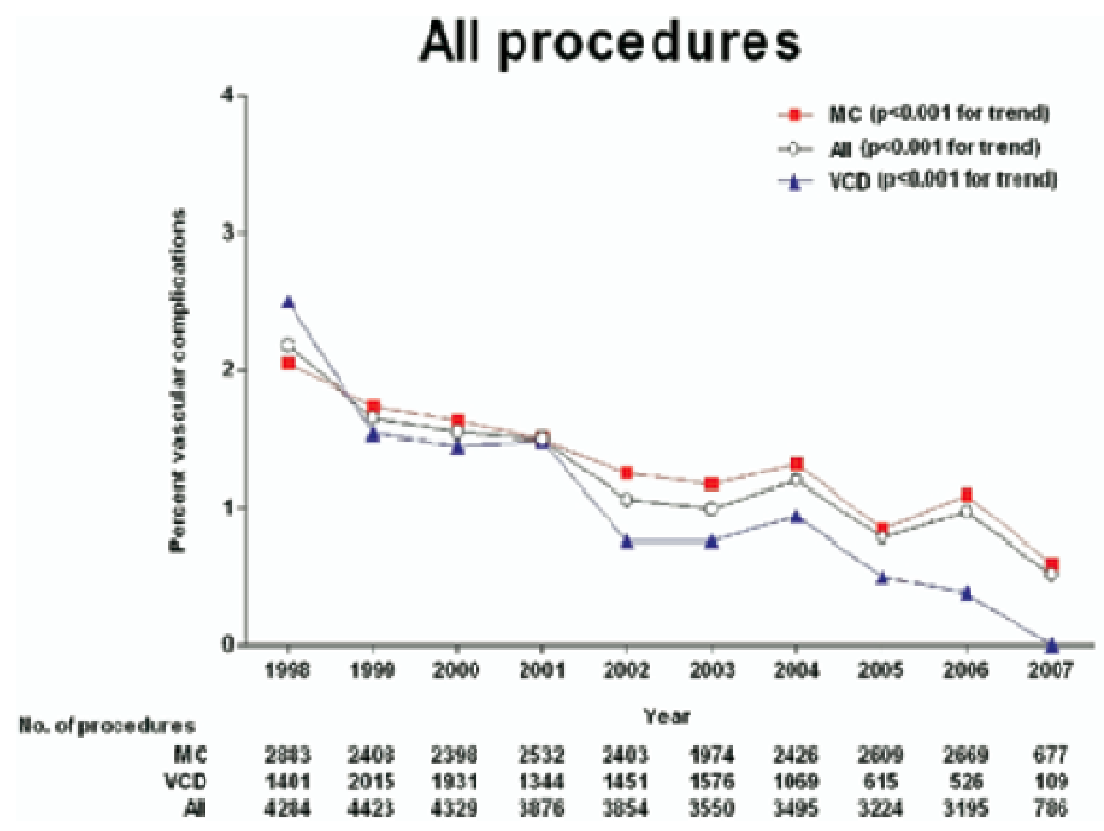

Figure 2. Any vascular complications by procedure and closure method. CATH - diagnostic cardiac catheterization; MC - manual compression; PCI - percutaneous coronary intervention; VCD - vascular closure device.(Applegate et al., 2008)

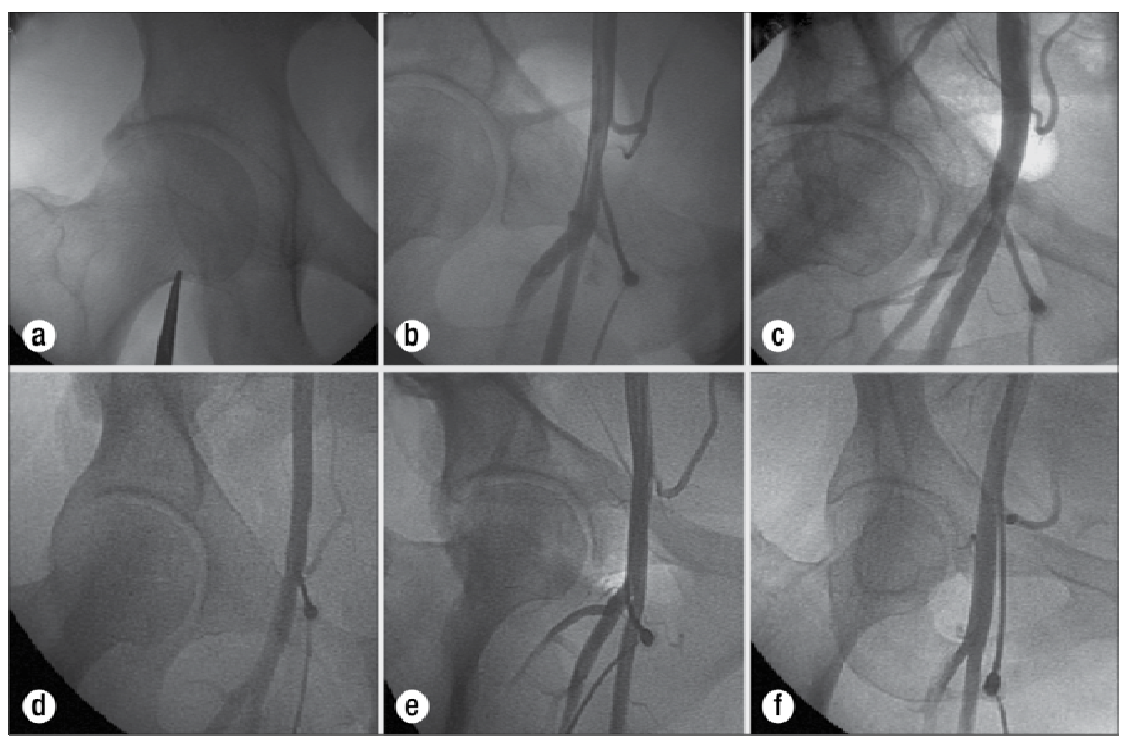

Figure 3. (a) Fluoroscopy of the femoral head utilizing forceps to note the position of the inferior border of the femoral head on the patient's skin. (b) Correct placement of the sheath in the common femoral artery. (c) Correct placement of the sheath in relation to the femoral head, with the arterial access incorrectly placed in the superficial femoral artery due to the anatomic variant of a high bifurcation. (d) Correct placement of the sheath in relation to the femoral head with a low hypogastric artery causing incorrect arterial placement in the external iliac artery. (e) Low sheath placement in the profunda femoris artery. (f) High sheath placement in the external iliac artery (Jacobi et al., 2009). 


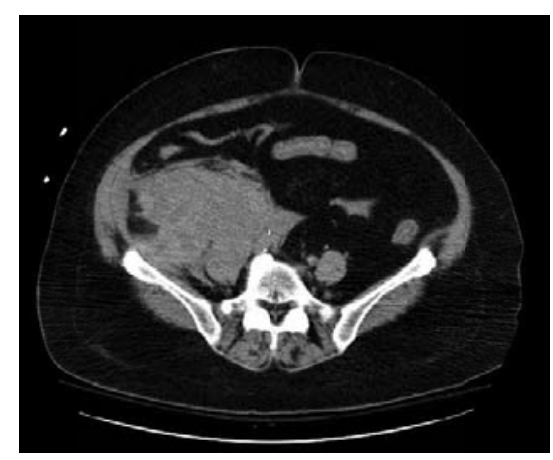

Figure 4. Retroperitoneal bleeding following cardiac catheterization via right femoral access.
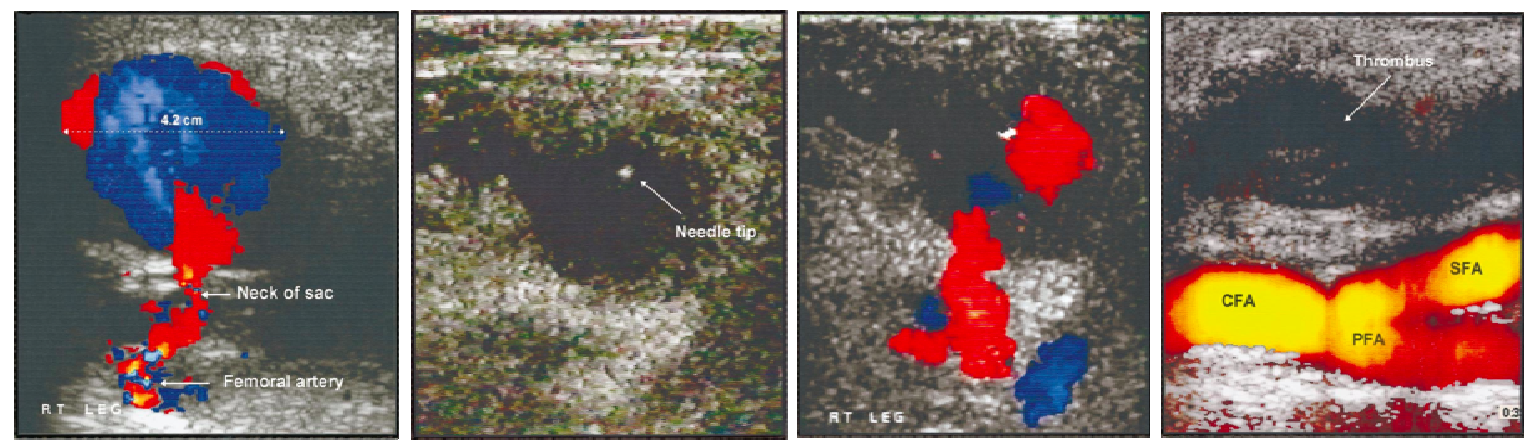

Figure 5. Duplex ultrasound image of pseudoaneurysm, demonstrating arterial flow through a long, narrow neck arising from defect in femoral artery and turbulent color flow into cavity (a). With color flow removed, exact position of needle tip can be identified at all times during procedure, because a small amount of echogenic thrombus forms at needle tip when thrombin comes into contact with blood, helping to guide needle placement (b). With needle in position, color flow during injection of thrombin confirms acute development of thrombus within sac (c). Power Doppler image of patent native fem- oral vessels (CFA indicates common femoral artery; SFA, superficial femoral artery; and PFA, profunda femoris artery) and absence of flow after successful thrombin injection into pseudoaneurysm cavity (d) (Lennox et al., 1999).

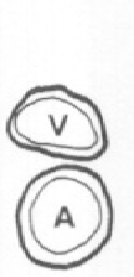

A

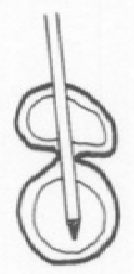

B

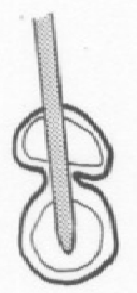

C

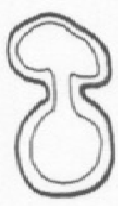

D

Figure 6. AVF result when needle tract crossing both artery and vein is dilated and catheterized. $\mathrm{V}=$ vein, $\mathrm{A}=$ artery(Kim et al., 1992) 


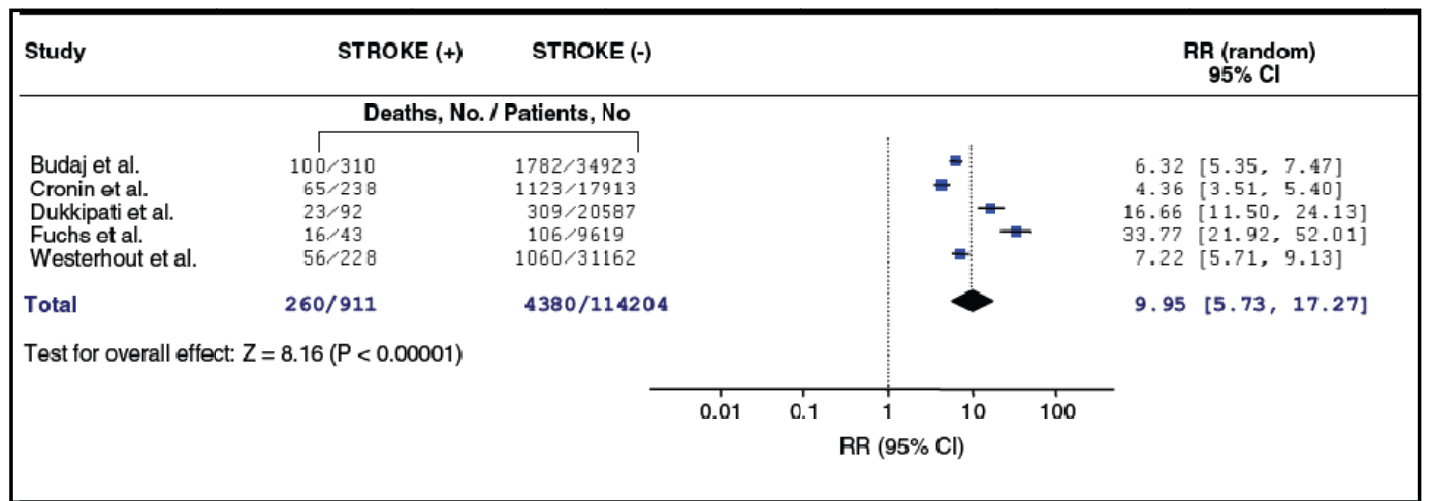

Figure 7. Pooled relative risk (random effects) of mortality after stroke in PCI or in patients with non STelevation MI
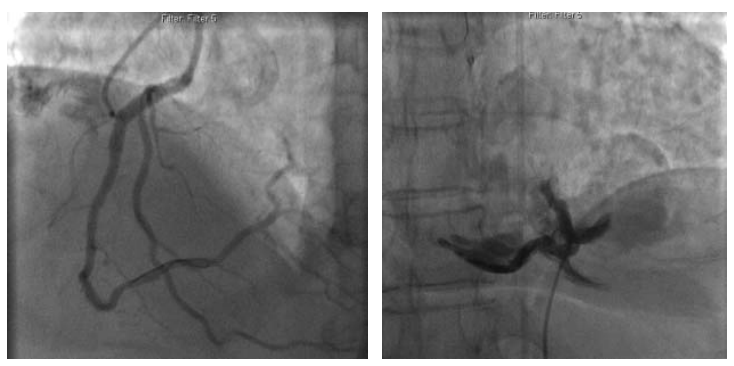

Figure 8 . Angiogram of right coronary artery before (a) and after perforation (b)
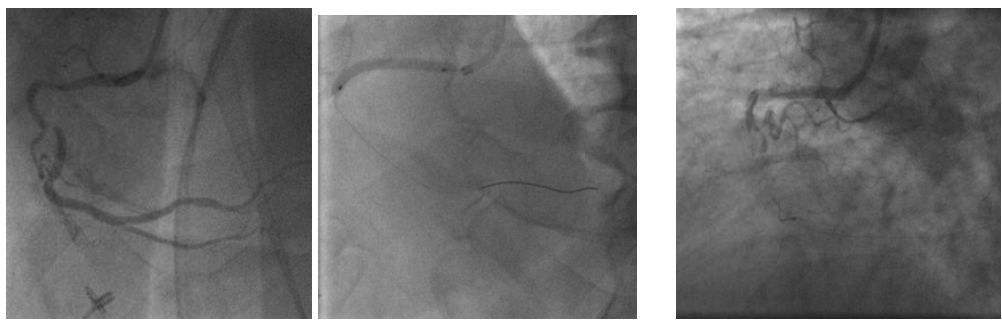

Figure 9. Angiogram of right coronary artery prior to intervention (a), after balloon angioplasty (b) and dissection (c)
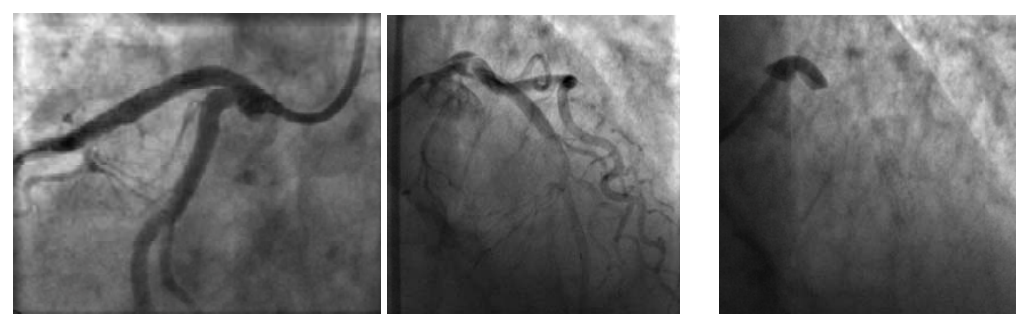

Figure 10. Angiogram of the left coronary system (a). Dissection of the left circumflex artery with guidewire catheter (b) with subsequent extension in to the left anterior descending artery (c) 